\title{
Psolidium bathygalego nom. nov. (Echinodermata, Holothuroidea) from bathyal bottoms of Galicia (NW Iberian Peninsula)
}

\author{
V. Urgorri ${ }^{1}$ (1) M. Candás ${ }^{1} \cdot$ G. Díaz-Agras ${ }^{1} \cdot$ X. Cunha-Veira ${ }^{1} \cdot$ C. Gómez-Rodríguez ${ }^{2} \cdot$ L. Míguez-Rodríguez $^{1}$
}

Received: 31 July 2020 / Revised: 30 November 2020 / Accepted: 1 December 2020 / Published online: 23 February 2021

(C) Senckenberg Gesellschaft für Naturforschung 2021

\begin{abstract}
It is proposed to name the Atlantic holothuria Psolidium complanatum Cherbonnier, 1969, whose denomination is already occupied by Psolidium complanatum (Semper, 1867) from the Philippines, as Psolidium bathygalego nom. nov. 843 specimens of Psolidium bathygalego nom. nov., collected between 417 and $1191 \mathrm{~m}$ deep in the NW and W of Galicia and in the Galicia Bank, were studied. A detailed description of the external and internal anatomy of Psolidium bathygalego nom. nov. is made by studying the ossicles and the skeletal structure by means of scanning electron microscopy (SEM) as well as the introvert, calcareous ring, retractor muscles, watervascular system, digestive system, respiratory trees, and reproductive system by means of micro-computed tomography (micro-CT). The habitat, feeding system, and geographical distribution of Psolidium bathygalego nom. nov. are also described.
\end{abstract}

Keywords Psolidae $\cdot$ Deep-sea $\cdot$ Anatomy $\cdot$ Habitat $\cdot$ Feeding $\cdot$ Micro-computed tomography

$\begin{array}{ll}\text { Abbreviations } \\ \mathrm{a} & \text { Anus } \\ \mathrm{c} & \text { Cloaca } \\ \text { cgm } & \text { Male gonadal tubule } \\ \mathrm{cgf} & \text { Female gonadal tubule } \\ \mathrm{cr} & \text { Calcareous ring } \\ \mathrm{cs} & \text { Cloacal suspensors } \\ \mathrm{e} & \text { Esophagus } \\ \mathrm{g} & \text { Gonoduct } \\ \mathrm{gb} & \text { Gonadal common base } \\ \mathrm{i} & \text { Intestine } \\ \mathrm{in} & \text { Introvert }\end{array}$

This article is registered in ZooBank under http://zoobank.org/ A05023A8-CACD-4D7C-9B7E-BFB6FAD6FABE

Communicated by S. Stöhr

\section{Urgorri}

vituco.urgorri@usc.es

1 Estación de Bioloxía Mariña da Graña, Universidade de Santiago de Compostela, rúa da Ribeira 1-4 (A Graña), 15590 Ferrol, Galicia, Spain

2 Departamento de Zooloxía, Xenética e AF, Universidade de Santiago de Compostela, rúa Lope Gómez de Marzoa, s/n Campus Vida, 15782 Santiago de Compostela, Galicia, Spain

$\begin{array}{ll}\text { lb. } & \text { Left branch tree } \\ \mathrm{mA} & \text { Longitudinal muscle A } \\ \mathrm{mB} & \text { Longitudinal muscle B } \\ \mathrm{mC} & \text { Longitudinal muscle C } \\ \mathrm{mD} & \text { Longitudinal muscle D } \\ \mathrm{mE} & \text { Longitudinal muscle E } \\ \mathrm{me} & \text { Mesentery } \\ \mathrm{mo} & \text { Mouth } \\ \mathrm{o} & \text { Ossicle trees } \\ \mathrm{p} & \text { Pharynx } \\ \mathrm{po} & \text { Podium } \\ \mathrm{pp} . & \text { Peripharyngeal sinus } \\ \mathrm{ps} & \text { Pharynx suspensors } \\ \mathrm{rA} & \text { Radial canal A } \\ \mathrm{rB} & \text { Radial canal B } \\ \mathrm{rC} & \text { Radial canal C } \\ \mathrm{rD} & \text { Radial canal D } \\ \mathrm{rE} & \text { Radial canal E } \\ \mathrm{rb} & \text { Right branch tree } \\ \mathrm{rc} & \text { Ring canal } \\ \mathrm{s} & \text { Stomach } \\ \mathrm{sc} & \text { Stone canal } \\ \mathrm{t} & \text { Tentacles } \\ \mathrm{ta} & \text { Tentacular ampullae } \\ \mathrm{v} & \text { Polian vesicle }\end{array}$




\section{Introduction}

During the French oceanographic prospecting campaign Thalassa, west of the coast of Brittany and the Bay of Biscay, a series of dredging operations were carried out in August 1967 at depths between 560 and $1100 \mathrm{~m}$, in which, among others, seventeen species of Holothuroidea were collected, four of which were new to Science (Cherbonnier 1969). One of them was described as Psolidium complanatum Cherbonnier, 1969, based on 25 specimens collected in bathyal bottoms at depths between 620 and $1045 \mathrm{~m}$, in three stations in the $\mathrm{W}$ of Galicia and in two stations in the $\mathrm{N}$ of Galicia. However, no specimens were collected in the stations sampled in the $\mathrm{W}$ of Brittany. One year later, during the second French oceanographic prospecting campaign Thalassa in October 1968, 71 more specimens of Psolidium complanatum were collected, which were obtained in twelve stations in the $\mathrm{W}$ and NW of Galicia at depths between 455 and $1000 \mathrm{~m}$ and 6 more specimens in Brittany at depths between 650 and $630 \mathrm{~m}$ (Cherbonnier 1970).

In the oceanographic campaigns Cangrexo-I-1991, DIVAArtabria-I-2002, DIVA-Artabria-I-2003, Vertidos-2004, Sarridal-2007, A-Selva-2008, DIVA-Artabria-II-2008, and DIVA-Artabria-II-2009, carried out by the Estación de Bioloxía Mariña da Graña of the Universidade de Santiago de Compostela, 843 specimens of this species of the genus Psolidium were collected. All of them were collected in the NW and W bathyal bottoms of Galicia and in the Galicia Bank, at depths between 417 and $1191 \mathrm{~m}$ (see Table 1 and Collection). The species proved to be very frequent and abundant, mainly on substrata of phosphorites and carbonate crusts, but it was also found on stone bottoms, gravel, and fragments of dead coral.

However, a century earlier, Semper (1867-1868) had described a new species from Zamboanga in the Philippines, which he had named Psolus complanatus, now formally admitted to the genus Psolidium (Rowe and Richmond, 2004; Ong et al. 2019) as Psolidium complanatum (Semper, 1867). Consequently, according to the ICZN (1999), the name Psolidium complanatum Cherbonnier, 1969 is not valid for the species described by Cherbonnier (1969) as it represents a junior homonym of Psolidium complanatum (Semper, 1867). Thus, the species of Cherbonnier (1969) should be renamed, and therefore, it is proposed to name it Psolidium bathygalego nom. nov.

In this paper, a thorough redescription of the external and internal anatomy of the species is made, since little reference of the internal anatomy had been made in the studies carried out so far on the species of the genus Psolidium Ludwig, 1886 (Cherbonnier 1969; Massin 1997; O'Loughlin and Ahearn 2008; O'Loughlin and Maric 2008). Most descriptions focus on the most conspicuous skeletal features of the external anatomy. Cherbonnier (1969) describes the internal anatomy of the animal briefly and incompletely in the original description of Psolidium complanatum. In addition, this paper provides new data on the biology and biogeographical distribution of Psolidium bathygalego nom. nov.

The redescription of the internal and external anatomy of Psolidium bathygalego nom. nov. was carried out by means of scanning electron microscopy (SEM) and micro-computed tomography (micro-CT). This is a non-invasive technique based on X-rays that measures the attenuation of the rays as they pass through an object, and makes it possible to obtain $2 \mathrm{D}$ and $3 \mathrm{D}$ images with very high resolution, without altering or destroying the sample. The use of micro-CT in the anatomical study of marine invertebrates has increased significantly in recent years, covering most zoological groups (Golding and Jones 2007; Alba-Tercedor and Sánchez-Tocino 2011; Haug et al. 2011; Faulwetter et al. 2013; Parapar et al. 2015, 2016; Candás et al. 2016, 2017; Parapar et al. 2017). The study of Echinodermata using this technique has so far focused on the skeletal structures of animals (Ziegler et al. 2008; Ziegler 2012; Okanishi et al. 2017; Stöhr et al. 2019).

\section{Material and methods}

Collection The 843 specimens studied were collected in the following oceanographic campaigns (Fig. 1b) conducted by the Estación de Bioloxía Mariña da Graña of the Universidade de Santiago de Compostela: Cangrexo-I-1991 carried out in the fishing area A Quiniela (W Galicia), at depths between 650 and $879 \mathrm{~m}$, on bottoms of phosphorites, carbonate crusts, calcareous plates, coal slag and small stones. DIVA-Artabria-I-2002, DIVAArtabria-I-2003, and Vertidos-2004 carried out at Ferrol Canyon and Coruña Valley (NW Galicia), at depths between 579 and $1132 \mathrm{~m}$, on bottoms of phosphorites, carbonate crusts, and gravel of corals and stones. Sarridal-2007 and A-Selva2008 carried out in the fishing area A Selva (N Galicia), at depths between 417 and $1064 \mathrm{~m}$, on bottoms of phosphorites, carbonate crusts, live and dead corals, and several types of gravel. DIVA-Artabria-II-2008 carried out in the fishing area A Quiniela (W Galicia), at depths between 503 and 1069 m, on bottoms of phosphorites, carbonate crusts, stones, and gravel. DIVA-Artabria-II-2009 carried out in the Galicia Bank, at depths between 830 and $1106 \mathrm{~m}$, on bottoms of phosphorites, carbonate crusts, and corals (see Table 1). Except for some specimens that were observed and photographed in vivo on board, all samples collected in the oceanographic campaigns were stored in 4\% formalin in 601 plastic drums. After sorting the specimens in the laboratory, they were stored in $70^{\circ}$ ethanol.

Ossicle preparations and measurements The preparations of the ossicles for their study under light microscopy (OM) and scanning electron microscopy (SEM) were made by macerating the organic matter with $5 \% \mathrm{NaClO}$ in an oven at $40{ }^{\circ} \mathrm{C}$. Specimens were measured with an eyepiece-micrometer on an Olympus SZX12 stereo microscope. In specimens that were in 


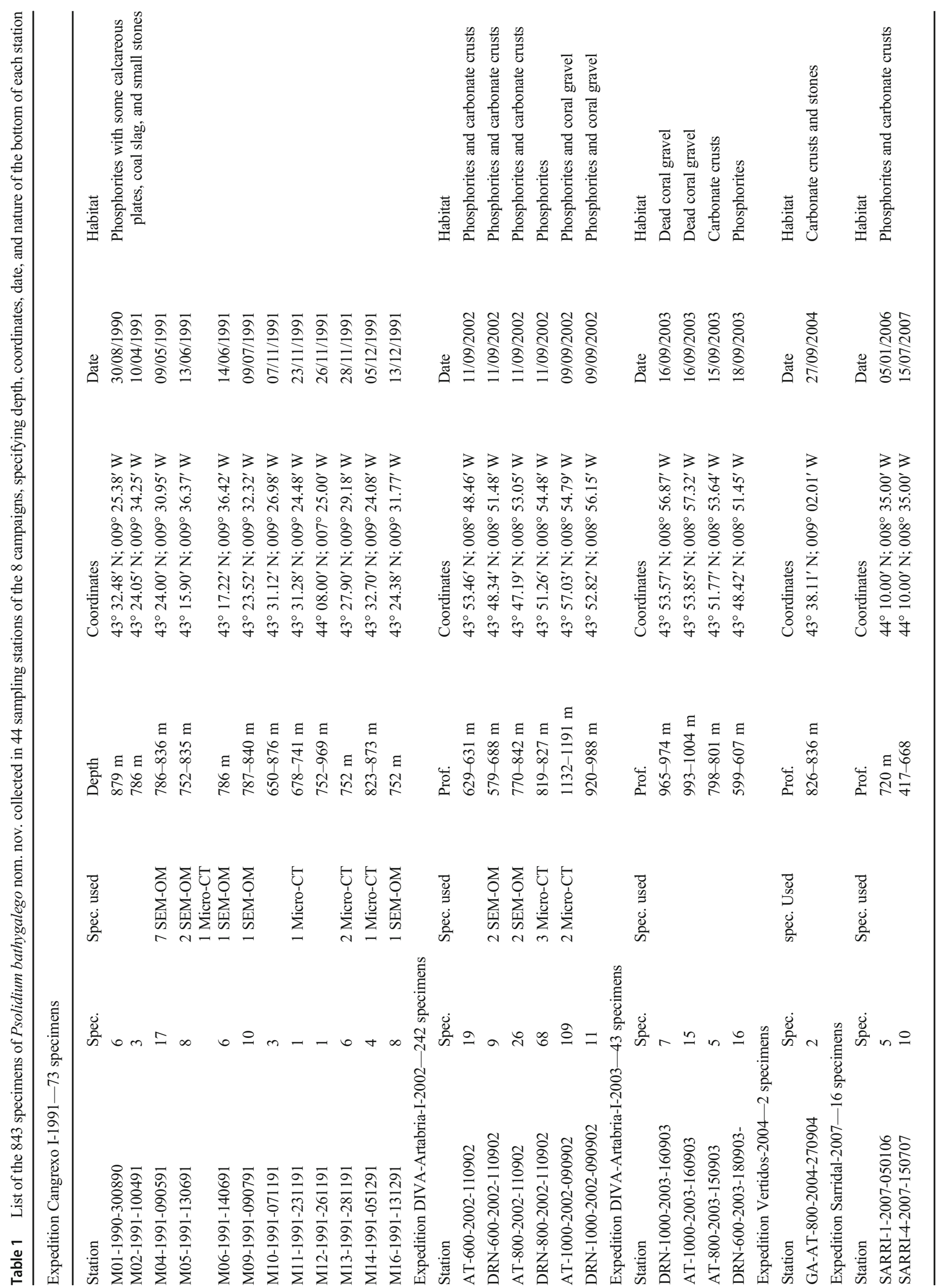




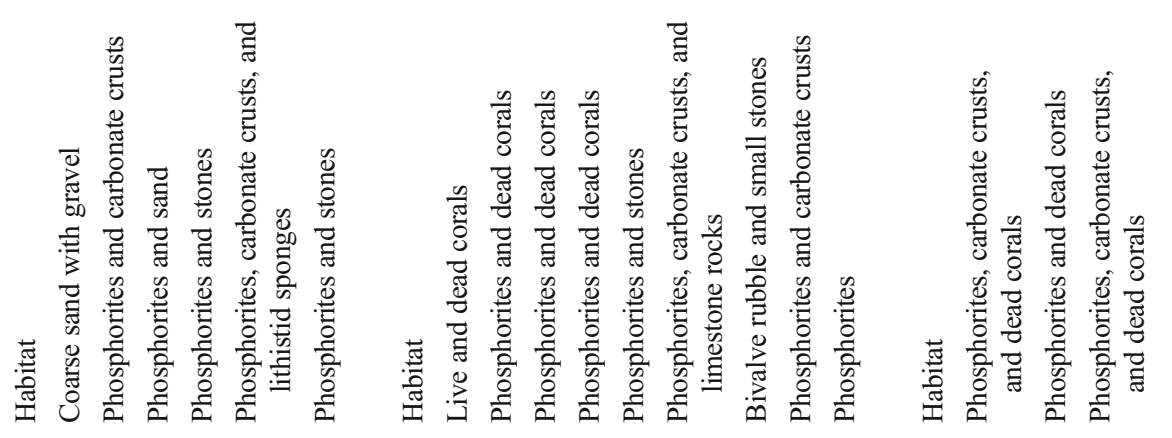

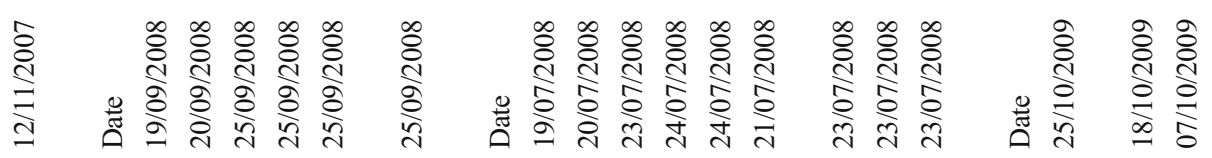

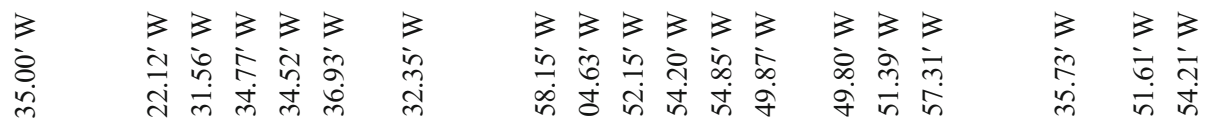

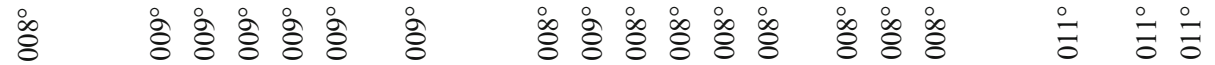

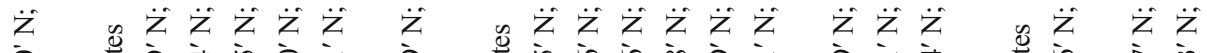

ठ․

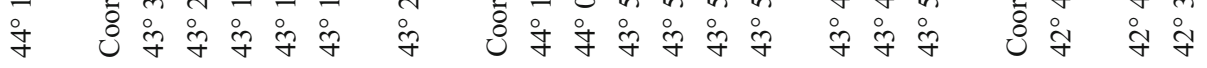

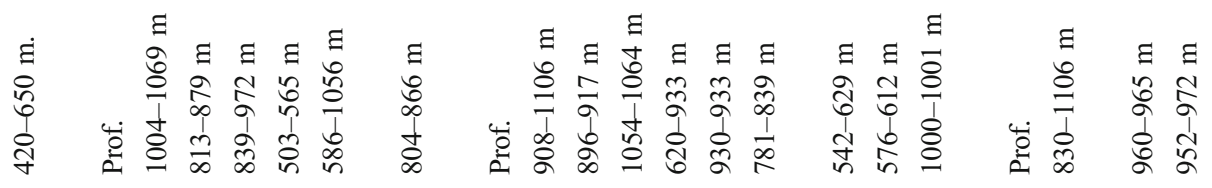

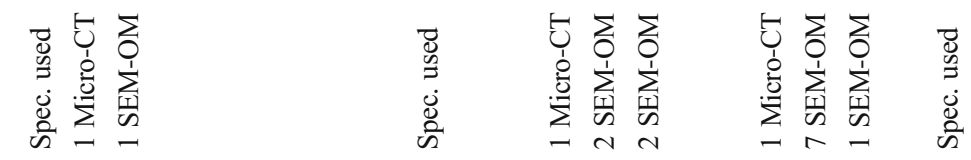

离

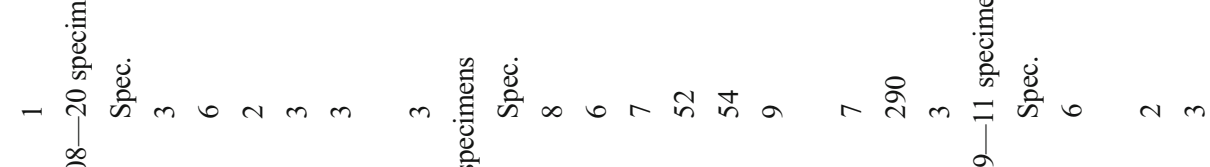

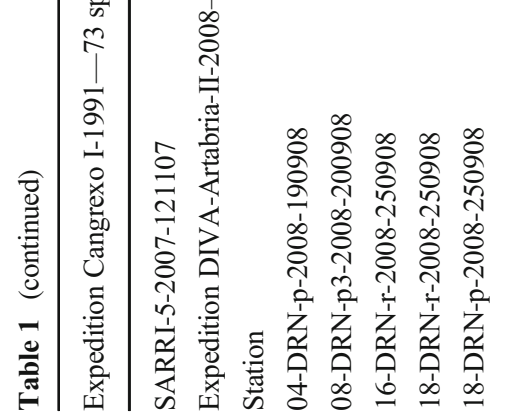
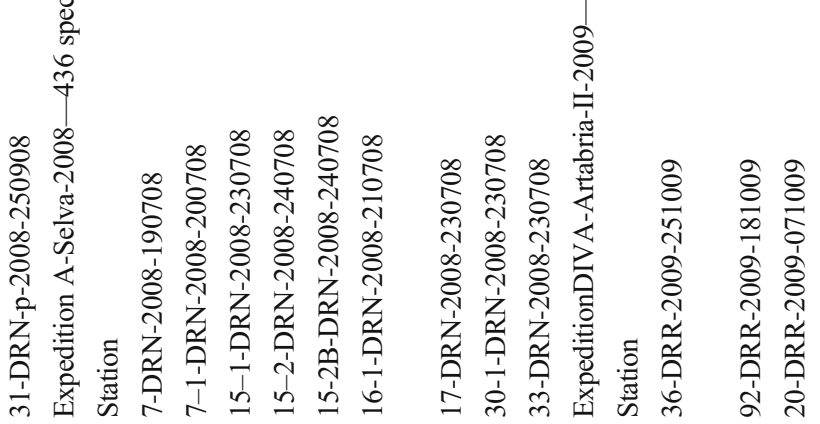
good condition, length and width were measured and the podia of the dorsal surface and those of the ventral sole margin were counted. The ossicles were studied and measured with a Scanning Electron Microscope ZEISS FESEM ULTRA PLUS and with a light microscope Olympus BX51TRF. A total of 29 specimens were macerated for the study of the ossicles under OM and SEM (see Table 1).

Micro-CT The external and internal anatomy of Psolidium bathygalego nom. nov. was studied by means of a Skyscan 1172 microtomograph (Bruker, Belgium) in which 13 specimens were scanned (see Table 1).

All specimens were dehydrated in successive ethanol baths $\left(80^{\circ}, 90^{\circ}\right.$, and $\left.96^{\circ}\right)$ and then stained with $1 \%$ iodine in $96^{\circ}$ ethanol for a week. Finally, they were immersed in hexamethyldisilazane (HMDS) for $2 \mathrm{~h}$ and left to air dry the night before the scanning (Alba-Tercedor and SánchezTocino 2011; Faulwetter et al. 2013).

The specimens were scanned with the Skyscan 1172 microtomograph, at resolutions between 1.5 and $3.5 \mu \mathrm{m}$ pixel size. The following parameters were used: $55 \mathrm{kv}, 165 \mu \mathrm{A}$, and no filter. The samples were rotated $360^{\circ}$, and the projection images were obtained at $0.20^{\circ}$ intervals. The images were reconstructed with the NRecon software (Bruker, Belgium), and the obtained sections were cleaned with the CTAnalyzer software (Bruker, Belgium). The software CTVox and DataViewer (Bruker, Belgium) were used for the correct visualization of the data.

After studying the sections obtained, 3D reconstruction was carried out using the program AVIZO 6.4 (Thermo Fisher Scientific) which allows three-dimensional anatomical models to be obtained from the two-dimensional images of the sections. After choosing the pixel size $(0.75 \mu \mathrm{m})$ and loading the cross-sectional images into AVIZO, they were aligned, drawing the different structures manually in the form of overlapping color layers and then smoothed, to eliminate imperfections in order to obtain a sharp three-dimensional image.

DNA analysis For molecular analysis, several gonadal tubules from three specimens (M14-1991-051291; M16-1991131,291; and DRN-600-2002-110,902) were soaked in water for $30 \mathrm{~min}$ before genomic DNA extraction with DNeasy Blood \& Tissue Kit (Qiagen, Germany). The 5' end of mitochondrial cox1 ("barcode region") was targeted with standard LCO/HCO primers (Folmer et al. 1994) and, independently, with primers $\mathrm{CO} 1 \mathrm{eF} / \mathrm{CO} 1 \mathrm{eR}$, following Miller et al. (2017). Amplification was performed with Bioline MyTaq and the following cycling: $94{ }^{\circ} \mathrm{C}$ for $5 \mathrm{~min}, 5$ cycles of $94{ }^{\circ} \mathrm{C}$ for $30 \mathrm{~s}$, $45^{\circ} \mathrm{C}$ for $1 \mathrm{~min} 30 \mathrm{~s}$ and $72{ }^{\circ} \mathrm{C}$ for $1 \mathrm{~min}, 35$ additional cycles of $94{ }^{\circ} \mathrm{C}$ for $30 \mathrm{~s}, 50^{\circ} \mathrm{C}$ for $1 \mathrm{~min} 30 \mathrm{~s}$ and $72{ }^{\circ} \mathrm{C}$ for $1 \mathrm{~min}$, and final extension of $72^{\circ} \mathrm{C}$ for $7 \mathrm{~min}$ in the case of $\mathrm{LCO} / \mathrm{HCO}$ and following the cycle in Miller et al. (2017) for CO1eF/CO1eR. Unfortunately, DNA extraction and amplification were not successful, probably due to the age and preservation mode of the samples, which was not suitable for molecular analyses. Recent attempts to collect new samples from live specimens have been thwarted by the Covid-19 pandemic.

\section{Results}

Phylum Echinodermata Bruguière, 1791 [ex Klein, 1734]

Class Holothuroidea de Blainville, 1834

Order Dendrochirotida Grube, 1840

Family Psolidae Burmeister, 1837

Genus Psolidium Ludwig, 1886

Type species: Psolidium dorsipes Ludwig, 1886 (type by monotypy)

Diagnosis Modified from Davey and Whitfield (2013), O'Loughlin and Maric (2008) and Ong et al. (2019). Dendrochirotid holothuroids; small, up to $40 \mathrm{~mm}$ long; midbody arched dorsally in transverse section, flat ventrally; dorsal and lateral body covered with imbricating scales, usually macroscopically conspicuous, sometimes obscured by integument, scales irregular in size and arrangement; scales decreasing in size ventrolaterally, orally and anally; lacking large oral valves; extensible oral cone with anterior, anterior-dorsal or dorsal orientation; extensible anal cone with posterior, posterior-dorsal or dorsal orientation; tube feet dorsally and laterally in mid-body, passing through scales.

Sole distinct, oval to elongate; discrete margin created by junction of small imbricating ventrolateral scales, with thinwalled, usually calcareous sole that lacks scales; peripheral band of tube feet, may be discontinuous across the interradii anteriorly and posteriorly; peripheral tube feet frequently of 2 sizes, those of outer series smaller; mid-ventral radial series of tube feet present or absent.

Calcareous ring solid, plates subrectangular, radial and interradial plates with tapered anterior projections; radial plates with deep notch posteriorly, interradial plates with shallow concave indentation posteriorly. Ten dendritic or finger shaped tentacles, rarely 8 tentacles; the two smaller ventral ones, rarely absent or with the end bifid and sometimes the upper tentacle of radius $\mathrm{C}$ also small and bifid.

Dorsal and lateral ossicles: multilayered or single-layered perforated plates (scales), always some with tube foot canals; integument covering scales may have cupped crosses, cups, 'thorn' ossicles (irregular branched rods pointed distally), buttons, perforated plates and rosettes; tube foot small endplates, and tube foot support ossicles that are irregular rods and plates, bent and curved, variably perforated.

Sole ossicles: interradii with small to large single-layered perforated plates (rarely with multilayering), smooth to variably knobbed and thickened, sometimes with cupped crosses, cups, thorn ossicles and rosettes; radii with additional tube 


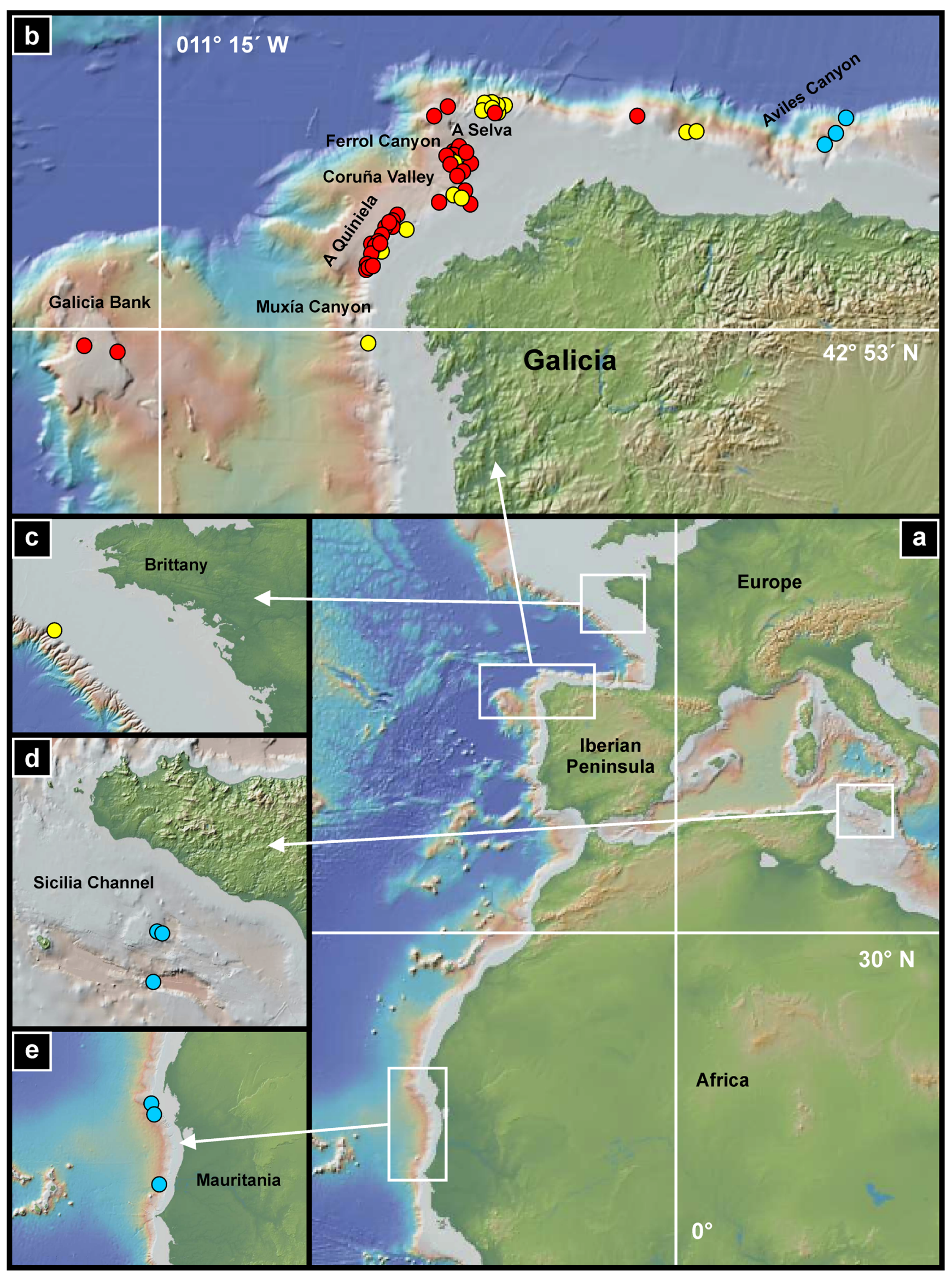


Fig. 1 Map of the distribution of Psolidium bathygalego nom. nov. to date. (yellow circle: Cherbonnier 1969, 1970; red circle: own data; blue circle: Massin 1997; Calero 2017; Fernández-Rodríguez et al. 2019). (Figures made with GeoMapApp (www.geomapapp.org)/CC BY)

foot ossicles, large endplates and tube foot support ossicles that are irregular rods and plates, bent and curved, variably perforated.

\section{Psolidium bathygalego nom. nov.}

http://zoobank.org/189C2033-A 704-4E04-BB9C1714B85FB8FA

Psolidium complanatum Cherbonnier, 1969: 355-357.

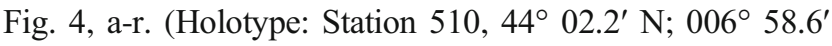
W, prof. 1000 m, roche, du corail. Est Galice, 10 août 1967) non Psolidium complanatum (Semper, 1867): Taf. XIII. Fig. 19. a-b. 1868: 61

Diagnosis Dendrochirotid holothuroid, small, up to $14 \mathrm{~mm}$ long, in vivo and fixed colouration white; oblong shape, rounded ends, convex back covered with macroscopic ossicles in plates, profusely perforated and inversely overlapping. Mouth and anus in oral and anal cones, extensible, in anterodorsal and postero-dorsal position; lacking valves. Flat and smooth ventral sole, with very fine tegument and numerous small perforated ossicles. Small and numerous dorsal tubular podia crossing the dorsal plates; ventral tubular podia arranged in two perimeter rows, one external with small podia and one internal with slightly larger podia. Ten long tentacles, contractile, digitiform and with arched perforated rods, of which the pair of the radius A and the upper tentacle of the radius $\mathrm{C}$ are smaller and bifid. Five terminal anal podia, digitiform and longer than the dorsal and ventral podia. Well-developed introvert reinforced by ossicles. The calcareous ring supports the pharynx and the ring canal by means of pharyngeal suspensors. It is formed by ten similar pieces, in the shape of an inverted Y, five interradial triangular and tapering and five radial with anterior rectangular projections with a distal cleft; the longitudinal retractor muscles are inserted in the latter. Longitudinal retracting muscles formed by five long and straight fascicles, arranged in a radial position. Ring canal of the water-vascular system with one Polian vesicle, one stone canal and 5 double radial canals in all its extension. Mouth in the center of the oral membrane with an annular sphincter; bulbous, thick-walled and muscular pharynx, which continues into a straight, tubular esophagus, which opens into the large, uniformly sized stomach. A long intestine begins after it with 4 sections, 2 ascending and 2 descending and ends in the rectum or cloaca, supported by cloacal suspensors and where the respiratory trees converge. These fork into two unequal branches, one to the left and the other to the right, which is the longest branch. They show numerous spiny ossicles under the epithelium. Separate sexes without sexual dimorphism, with a fasciculate gonad of gonadal tubules, ending in a short gonoduct, which opens through the gonopore between the oral tentacles of the inter-radius CD and without genital papilla. Female gonadal tubules, claviform or moniliform, with large oocytes, between 16 and 39 per gonadal tubule and cylindrical male gonadal tubules, long and of uniform diameter; both arranged, without apparent order, in the coelom of the body cavity, varying in number between 8 and 14 in both sexes. The gonadal tubules show small subepithelial ossicles, mostly in the shape of a more or less elongated $\mathrm{X}$.

Material examined A total of 843 specimens collected from 43 stations in the eight oceanographic campaigns described in the Collection section (vide supra) were studied. Table 1 specifies the number of specimens collected at each sampling station, their depth, coordinates, date of sampling, and nature of the bottom of each station where they were collected.

A total of 180 well-preserved specimens were measured, $85 \%$ of which were between 4 and $10 \mathrm{~mm}$ in length and 2 to $6 \mathrm{~mm}$ in width. The width ratio of $70 \%$ of the specimens measured corresponds to $40-60 \%$ of the length. It should be noted that although some specimens were photographed in vivo on board, none were anesthetized, so when fixed directly in the sample, the body length-width ratio varies depending on whether the specimens were attached to the substratum or detached from it.

Deposit The entire collection of Psolidium bathygalego nom. nov., preserved in $70 \%$ ethanol and 40 preparations of ossicles and body fragments for their study under SEM, have been deposited at the Museo de Historia Natural of the Universidade de Santiago de Compostela, Galicia, Spain, with the deposit number: MHN-USC-10115.

Derivatio nominis From the Greek bathys: depth, referring to the bathyal depth at which the species was collected and galego from the Galician language, a word that means native to or from Galicia (NW Iberian Peninsula), used as a noun in apposition.

\section{Description}

\section{External anatomy}

Habitus Small animals, elongated body, up to $14 \mathrm{~mm}$ length, $7.5 \mathrm{~mm}$ wide. Smallest specimen to $1.5 \mathrm{~mm}$ length and $0.7 \mathrm{~mm}$ wide. Uniform white color, except in the area of the ventral sole that is slightly yellowish; the viscera can be 

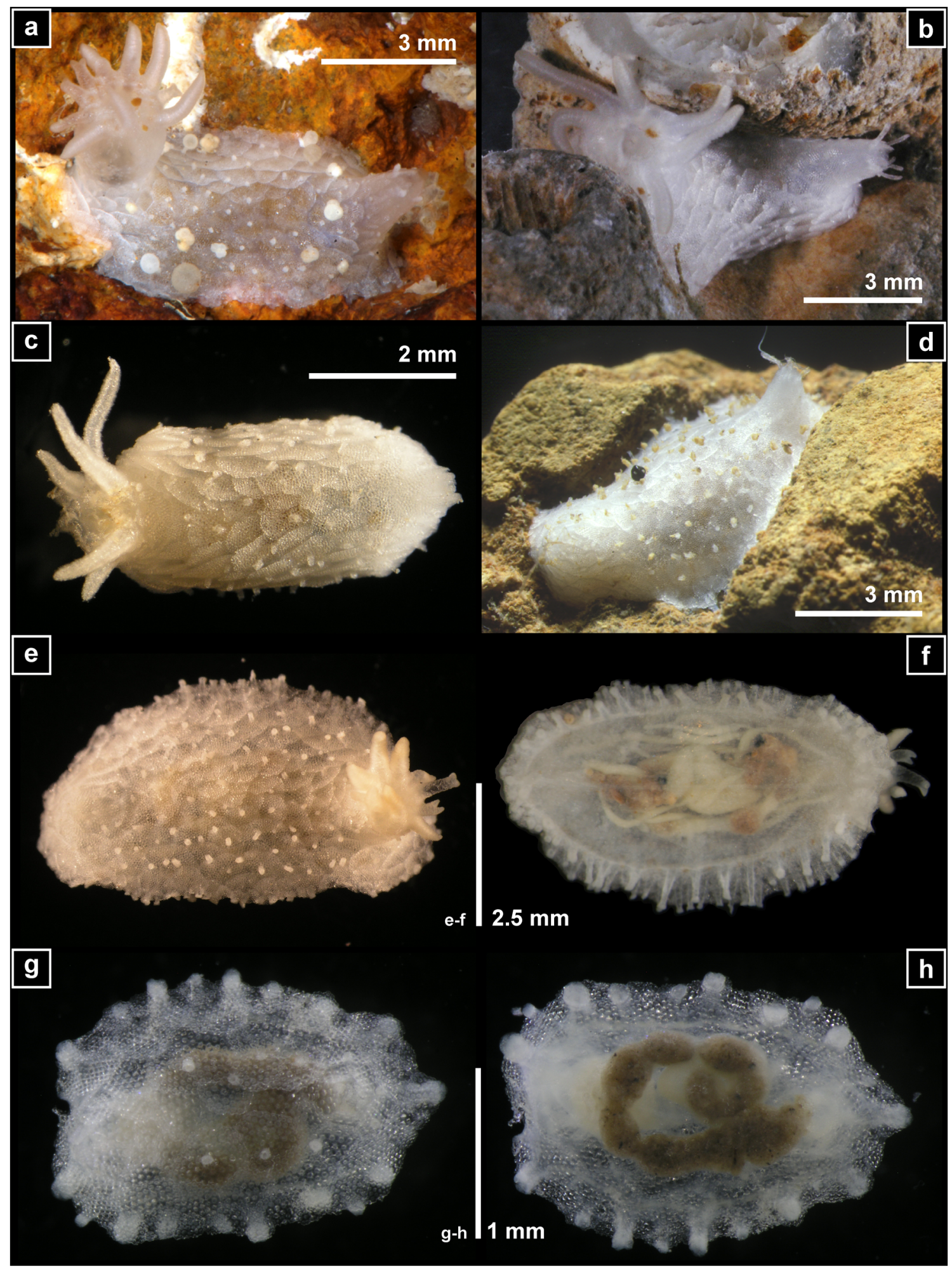

Fig. 2 Psolidium bathygalego nom. nov. Habitus and details of the external appearance. a $8.5 \mathrm{~mm}$-long specimen in vivo (Stn. 20-DRR2009-071009); b $7.1 \mathrm{~mm}$-long specimen in vivo (Stn. AT-1000-2002090902); c 5.4 mm-long specimen in vivo (Stn. AT-1000-2003-

observed thanks to the transparency of its thin tegument (Fig. 2a-h). Body oblong, with rounded anterior and posterior
160903); d 8 mm-long specimen in vivo (Stn. M16-1991-131291); e, f Dorsal and ventral view of a $7 \mathrm{~mm}$-long preserved specimen (Stn. 30-1DRN-2008-230708); g, h Dorsal and ventral view of a $2.3 \mathrm{~mm}$-long preserved specimen (Stn. 7-1-DRN-2008-200708)

ends and a convex back completely covered with plate-shaped ossicles (Figs. 2a-e and 9a). Semicircular body section, 
moderately low in vivo and higher in fixed specimens, being ventrally flat (Fig. 9b). The mouth and the anus open dorsally near the respective dorsal-anterior and dorsal-posterior ends, through two cone-shaped subterminal protuberances, covered by plates. The oral cone is larger in diameter and height than the anal cone; there are no valves in either cone (Fig. 9c, d). The mouth is bordered by ten tentacles that correspond to the five radii of the water-vascular system, with a pair of tentacles on each radius (Fig. 3a).The tentacles are contractile, long, and unbranched, digitiform when extended and conical when contracted (Fig. 2a-c); they are all of similar size, except for the mid-ventral pair of radius A (A1-A2) and the upper tentacle of radius $\mathrm{C}(\mathrm{C} 2)$ of the bivium which are the three shortest and with the apex bifid (Fig. 3a, b, d). The introvert is only externally visible when completely protruded (Fig. 2a). In the anal cone, five terminal anal podia located subappically; they are digitiform and longer than the dorsal and ventral podia (Fig. 3c, f). These represent, at the posterior end of the body, the radial canals that end as the last podia surrounding the anus.

Numerous dorsal podia protrude from the plate-shaped dorsal ossicles (Figs. 2a-e, g, and 3e). All podia are of similar size, thin and narrow, dispersed over the entire dorsal surface, including the oral and anal cones (Figs. 9c-d), without any apparent distribution. They emerge through the plates, one or two per plate, exceptionally three (Fig. 4d). In very small specimens, the dorsal podia are always in the upper half of the body (Fig. $2 \mathrm{~g}$ ). The dorsal podia of 160 specimens were counted, of which $70 \%$ had between 30 and 80 podia in specimens with lengths between 8.5 and $13 \mathrm{~mm}$. However, the number of dorsal podia is not related to the length of the animal; thus, four specimens of 7.5, 10, 11.4, and $12.5 \mathrm{~mm}$ in length had $133,112,125$, and 114 dorsal podia respectively, and in another four of 3.5, 6.1, 9, and $13 \mathrm{~mm}$ in length, they had 29, 16, 24, and 73 dorsal podia, respectively.

The ventral region or sole is flat and smooth, with a very thin tegument, almost transparent, with the viscera of the general body cavity visible through it (Figs. $2 \mathrm{f}, \mathrm{h}$, and $3 \mathrm{j}$ ) and protected by numerous small ossicles (Fig. $5 \mathrm{~s}$, t). The sole presents marginally in all its contour two rows of ventral tubular podia, more robust than the dorsal podia; they are arranged in an external perimetral row of small tubular podia and another more internal perimetral row of tubular podia, less numerous and of slightly bigger size, between 25 and $30 \%$ of extra diameter (Fig. 6g-i). The external podia are very close to the body margin and lie radially, while the internal podia, separated from the margin, are arranged vertically to the sole (Figs. $3 \mathrm{~g}$ and $6 \mathrm{~g}$ ). The mid-ventral radius $\mathrm{A}$ is devoid of tubular podia, except for two specimens that showed 3 and 4 podia, respectively, in the anterior and posterior regions of radius A (Fig. 3 h).

It should be noted that there is no specific relationship between the number of ventral tubular podia and the length of the animal. We counted the ventral tubular podia of 92 specimens, of which the longest $(13 \mathrm{~mm})$ had 74 podia, 51 external and 23 internal; the next in length $(12.5 \mathrm{~mm})$ had 116 pods, 80 external and 36 internal; a specimen of lesser length $(9.7 \mathrm{~mm})$ had the greatest number of podia counted, 119 podia, 71 external and 48 internal. Finally, a specimen smaller in length $(5.5 \mathrm{~mm})$ showed 74 podia, 47 external and 27 internal, as many as the specimen of the greatest length $(13 \mathrm{~mm})$.

In the same sense, it can be said that there is also no certain proportion between the number of external and internal ventral tubular podia. Thus, the external and internal ventral tubular podia counted in 92 specimens are in a proportion that goes from triple (ext./int. $=3$ ) to the same number of podia (ext./int. $=1$ ), of which $50 \%$ of the specimens presented a proportion between external and internal podia from 1.5 to $2,23 \%$ from 2.1 to 2.5 , and $13 \%$ from 1.1 to 1.4 . However, in very small specimens, smaller than $2.5 \mathrm{~mm}$ in length, the number of external and internal podia is the same or very difficult to distinguish from each other; in the 2 smallest specimens observed $(1.5 \times 0.7 \mathrm{~mm}$ and $1.7 \times 1 \mathrm{~mm})$, they had a total of 10 and 14 podia of the same size in a single perimeter row, respectively.

In certain specimens, brown spots are observed located between the internal ventral podia and arranged in an oval that runs along the ventro-lateral radii B and E (Fig. 3j). In some specimens, coinciding with the back of the mid-ventral ambulacrum A, they present a larger spot and small spots scattered throughout the ventral surface (Figs. 3h, j). In other specimens, the presence of the brown spots is less, being limited to the spaces between the internal ventral podia of the back of the animal. In the 843 specimens, the presence of these brown spots was counted and detected only in 110 specimens, of which 61 corresponded to a single station: $30-1-\mathrm{DRN}-2008$ 230708.

The brown spots are not superficial, but are located on the internal surface of the tegument of the ventral sole. At SEM they are observed as ovate clusters, from 9 to $19 \mu \mathrm{m}$ in length and from 4 to $11 \mu \mathrm{m}$ in width, formed by small granules from 2 to $3.3 \mu \mathrm{m}$ in diameter (Fig. 3k); they are very numerous in the spots of the spaces between the internal ventral podia (Fig. $3 \mathrm{~m}$ ) and isolatedly dispersed throughout the ventral surface of the sole, with slightly different sizes (Fig. 3n). In some areas, the small granules do not form ovate clusters, agglutinating in shapeless masses of much larger size (Fig. 3o). In the specimens counted, the brown spots did not appear in the very small specimens.

Ossicle and skeletal structure The entire body surface, dorsal and ventral, and the different types of podia are covered with dermal calcareous ossicles.

Dorsal ossicles arranged in plates The entire convex dorsal surface is completely covered by large calcareous plates 


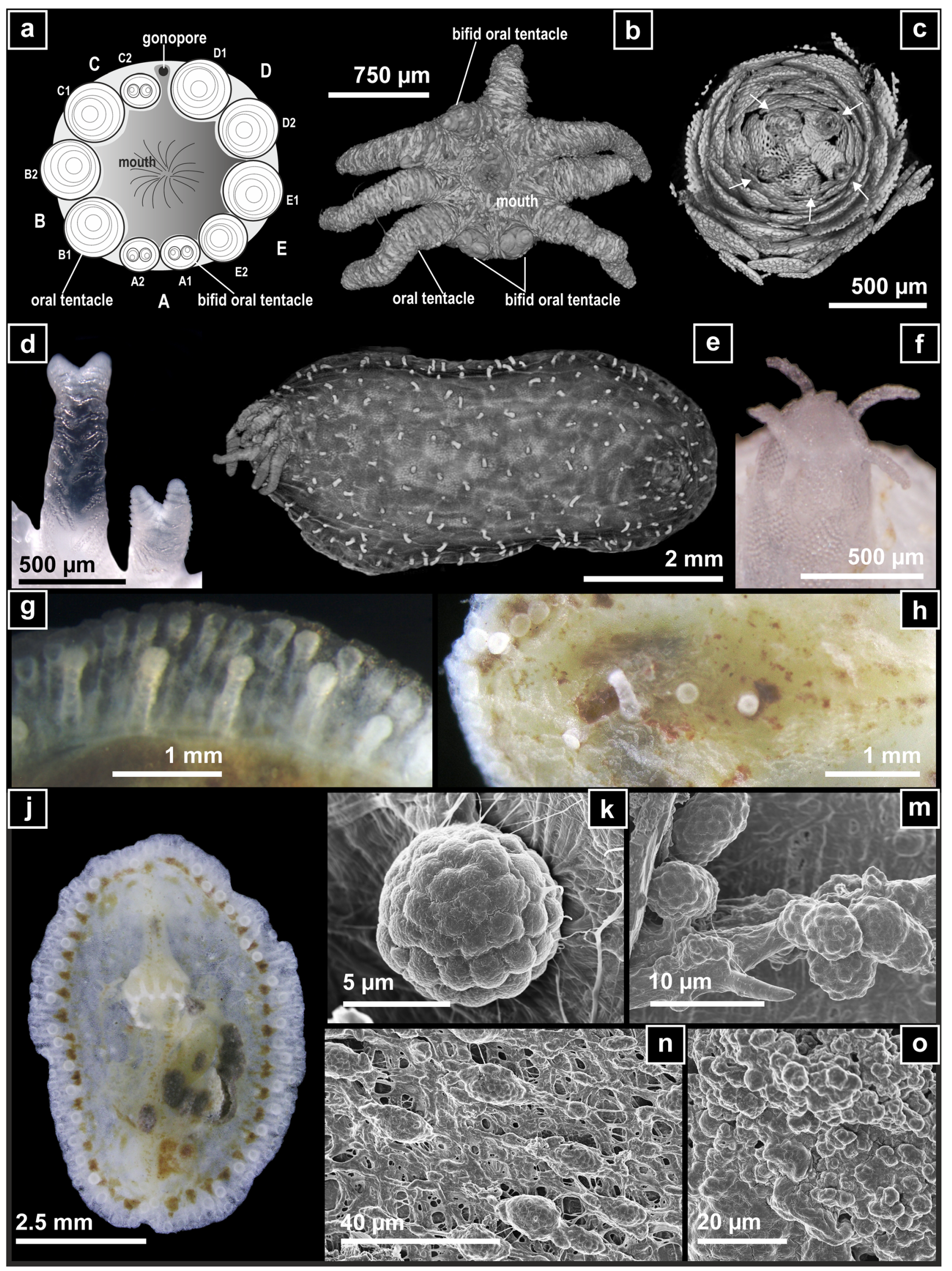


Fig. 3 Psolidium bathygalego nom. nov. a Pattern of the tentacles of the oral area. A: mid-ventral radius; $\mathrm{B}$ and $\mathrm{E}$ : ventro-lateral radii; $\mathrm{C}$ and $\mathrm{D}$ : dorsal-lateral radii; $\mathbf{b}$ Oral area and oral tentacles; $\mathbf{c}$ Apical area of the anal cone with the five anal podia (arrows); $\mathbf{d}$ Oral bifid tentacles in vivo of the radius A; e Arrangement of the dorsal podia; $\mathbf{f}$ Anal cone with the five anal podia in vivo; $\mathbf{g}$ Arrangement of the ventral perimeter podia; $\mathbf{h}$ Specimen with 4 medial podia in the radius $\mathrm{A} ; \mathbf{j}$ Brown spots between the podia of the internal perimeter row; $\mathbf{k}-\mathbf{m}$ Ovate clusters of small granules of the brown spots between the ventral podia; n Ovate clusters in the brown spots on the ventral sole; o Shapeless masses of small granules of the brown spots. (b, c, e Micro-CT; k-o SEM)

(Fig. 2a-e, g), with irregular margins, profusely perforated and rounded but with a very variable shape: circular, ovoid, oblong, quadrangular, and others (Fig. $4 \mathrm{a}-\mathrm{g}$ ). Their size is very different, from $1500 \times 1100 \mu \mathrm{m}$, the largest, to $192 \times$ $177 \mu \mathrm{m}$, the smallest; of 100 ossicles arranged in plates measured, $65 \%$ are between $800 \mu \mathrm{m}$ and $1200 \mu \mathrm{m}$ long and $600 \mu \mathrm{m}$ to $900 \mu \mathrm{m}$ wide.

All the dorsal plates are profusely perforated by small holes, mostly circular but also oval. The holes are of unequal diameters ranging from $9.8 \mu \mathrm{m}$ to $50.4 \mu \mathrm{m}(\bar{x}: 25.7 \mu \mathrm{m})$, without a regular distribution, but being much more numerous than those of small and medium diameter. Large holes are often in the central area of the plate and their maximum diameter increases with plate size, from $25 \mu \mathrm{m}$ in very small plates to $35 \mu \mathrm{m}$ in medium plates and $43-50 \mu \mathrm{m}$ in large plates. The holes of the dorsal podia also appear in the dorsal plates (Fig. 4a-g). These are irregularly shaped and vary from $48 \times 45 \mu \mathrm{m}$ to $125 \times 77 \mu \mathrm{m}(\bar{x}: 75 \times 55 \mu \mathrm{m})$ in 20 holes measured.

The dorsal plates that cover the entire back of the animal are inversely imbricated, so that each plate of the first row of the lower margin overlaps the plates of the second line immediately above and these in turn overlap the plates of the third row and so on until the plates of both sides converge in the mid-dorsal area, increasing in size from the margin to the middorsal line (Figs. 4a, b, and 9a, b). The mid-dorsal end plates of each side overlap one on top of the other alternately; in adult specimens there are 8 to 10 plates between the oral and anal cones (Fig. 9a).

The smaller dorsal plates are those corresponding to the lower margin row around the margin of the back and are characterized by a straight lower margin, which gives them a fan shape (Figs. 4a1, b1, f, g, and 9b). The plates in the second row are larger (Fig. 4a2, b2), generally more than twice as large as those in the first row. The successive rows, in number from 6 to 8 , increase in size towards the mid-dorsal area, where the largest are located (Fig. 4a, b). All the rows of plates cover completely the whole animal, also going up the oral and anal cones, where they are smaller plates that decrease in size towards the apex of the cone (Fig. 9c, d).

The dorsal plates are smooth on their ventral or internal side (Fig. 4b, c, g), while on the dorsal or external side they have two distinct areas (Fig. 4a, d-f): the middle and upper areas are tuberculate, while the lower or lower-lateral area is smooth, like the internal face of the plate, which corresponds to the area covered by the preceding plate or plates; some middorsal plates only have the central area tuberculate because they are partially covered by preceding plates on both sides (Fig. 4e). The external tuberculate area of the dorsal plates presents an ornamentation that varies from smooth to strongly spinulose tubercles, with plates with different degrees of spinulation, even within the same specimen (Fig. 4j-m). The dorsal plates have one or two holes of larger diameter, more rarely three or none, corresponding to the dorsal podia that cross them (Fig. 4a-e).

The dorsal plates are structurally composed of two sheets (Fig. $4 n$ ), the base sheet which is smooth on both sides, highly perforated and which determines its size, and an additional tuberculate sheet which develops over the base sheet in the central area of the external face and in other uncovered areas, thus generating a more robust and solid three-dimensional structure made up of tubercles connected to each other by narrow calcareous bridges (Fig. $4 \mathrm{j}-\mathrm{m}$ ).

The dorsal plates surround the base of the oral and anal cones, through which they ascend with successively smaller but equally imbricated plates, like the dorsal ones (Fig. 9c, d). The cone plates are triangular in shape and become narrower as they approach the apex of the cone. Their distal holes are generally of greater diameter, having very small tuberculate areas, only at the top; the rest of the plate is smooth on both sides (Fig. 4h, i). The plates of the oral cone (Fig. 4h) range from $506 \mu \mathrm{m}$ to $1051 \mu \mathrm{m}(\bar{x}: 757 \mu \mathrm{m})$ long; they are slightly more robust and larger than those of the anal cone (Fig. 4i), whose lengths vary from $362 \mu \mathrm{m}$ to $651 \mu \mathrm{m}(\bar{x}: 564 \mu \mathrm{m})$. The oral and anal cones lack valves; however, at the end of the anal cone and in internal position to the anal podia, there are five small plates that fold over the anus lumen (Fig. 3c).

Ossicles of the ventral sole The sole of the ventral region is flat and is reinforced by numerous ossicles scattered throughout the tegument, but without contacting each other (Fig. $5 \mathrm{~s}$, t). The ossicles are small, flattened and mostly with 3 or 4 holes, of which two are larger, arranged transversely, and another two are smaller, arranged longitudinally, which gives the ossicle a certain rhomboidal cruciform appearance (Fig. 5f, g), with lengths between $65 \mu \mathrm{m}$ and $107 \mu \mathrm{m}(\bar{x}: 82.5 \mu \mathrm{m})$. Other ossicles with 1 or 2 holes (Fig. 5a-e) are smaller, between $50 \mu \mathrm{m}$ and $93 \mu \mathrm{m}$ long $(\bar{x}: 75.4 \mu \mathrm{m})$; they are very rare and represent developing ossicles. There are also larger ossicles with a greater number of holes, between 5 and 16 , with a shape similar to that of 4 holes but surrounded by one, two or several smaller holes (Fig. 5h-q), with lengths between $77 \mu \mathrm{m}$ and $183 \mu \mathrm{m}(\bar{x}: 109.2 \mu \mathrm{m})$. These ossicles are located exclusively on the sole that surrounds the ventral perimeter podia (Fig. 5t). All the ossicles of the sole are bordered by short blunt spines. 
Very rarely, ossicles of similar shape appear, but with exceptionally large holes, more than double the size of the others and without blunt spines (Fig. 5r).

Ossicles of the ventral perimeter podia The lateral ambulacra $\mathrm{B}$ and $\mathrm{E}$ have a double row of ventral perimeter podia on the margin of the sole, an external row with smaller and more numerous podia and an internal row with larger and fewer podia (Figs. 2f, h, $3 \mathrm{~g}$, j, and $6 \mathrm{~g}-\mathrm{i}$ ). Both types of podia show similar structure, with elongated perforated ossicles that reinforce the tubular wall and a circular plate at the end of the podium. The end plate of the podia, of circular configuration, is profusely perforated, with holes of different diameter and without a determined distribution, since in some plates the large holes are central while in others they are peripheral (Fig. 6a, b). Of 70 end plates measured, the largest was $274 \mu \mathrm{m}$ in diameter with 13 transverse holes and the smallest $96 \mu \mathrm{m}$ with 6 holes. However, the terminal plates of 10 external and 10 internal podia of the same specimen were studied, and it was found that the plates of the large internal podia had a diameter between $175 \mu \mathrm{m}$ and $205 \mu \mathrm{m}$, with 10-12 transverse holes, while the diameter of the plates in the small external podia, fluctuated between $120 \mu \mathrm{m}$ and $150 \mu \mathrm{m}$, with 6-8 transverse holes, which represents $70 \%$ of the diameter of the large plates (Fig. 6a, b).

The elongated, perforated ossicles of the tubular wall of the podia can be classified into four types. The first are ossicles with a short central rod that expands at both ends with a few holes and with small blunt spines on the margin (Fig. 6c); their size varies from $97 \mu \mathrm{m}$ to $203 \mu \mathrm{m}(\bar{x}: 123.4 \mu \mathrm{m})$, and they are mostly curved, to adapt to the margin of the terminal plate where most are located (Fig. 6a5, g-i). The second and third types correspond to elongated perforated and slightly curved ossicles that are characterized by showing, respectively, one or two large central transverse holes, with small blunt spines all around (Fig. 6d, e), having a respective length of 78$164 \mu \mathrm{m}(\bar{x}: 116.1 \mu \mathrm{m})$ and $82-172 \mu \mathrm{m}(\bar{x}: 127.2 \mu \mathrm{m})$; they are the most abundant ossicles in both podia and are located in the tubular wall of the podia, interspersed with each other in an oblique arrangement (Fig. 6g-i).The fourth type of ossicles has the appearance of small plates, with several holes, large and small, and with short blunt spines on the margin (Fig. 6f); they are the widest, with a length of $83-133 \mu \mathrm{m}(\bar{x}$ : $112.4 \mu \mathrm{m})$, and are located at the base of the tubular wall of the podia (Fig. 6g).

Ossicles of the dorsal podia The thin, narrow dorsal podia are arranged over the entire dorsal surface, including the oral and anal cones (Figs. 2a-e, g, 3e, and 9c, d). These podia have a structure similar to the ventral perimeter podia, with perforated ossicles that reinforce the tubular wall and a circular plate at the end of the podium. The end plate of the podia, of circular configuration, is completely perforated, with holes of different diameter and shape and without a determined distribution (Fig. 7a); the diameter of the plates varies between 59 and $71 \mu \mathrm{m}$, with $10-18$ holes per plate.

The perforated ossicles of the tubular wall of the dorsal podia can be classified into the same four types as those of the ventral perimeter podia, with the difference that they are very curved lengthwise (to adapt to the much smaller diameter of the dorsal podia), proportionally wider and show fewer holes and a larger relative diameter (Fig. 7b-e). The first type of ossicles of the dorsal podia has a short central rod and small dilations at both ends with small blunt spines and one or two holes (Fig. 7b); their size varies from $55 \mu \mathrm{m}$ to $73 \mu \mathrm{m}(\bar{x}$ : $64.4 \mu \mathrm{m})$, and they are located at the margin of the terminal plate (Fig. 7j).The second and third types correspond to perforated ossicles, which are very curved and are characterized by showing one or two large central transverse holes, with few holes on each side and small blunt spines on the lateral and upper margins, respectively (Fig. 7c, d). They are 56-78 $\mu \mathrm{m}$ $(\bar{x}: 65.3 \mu \mathrm{m})$ and $59-77 \mu \mathrm{m}(\bar{x}: 66.3 \mu \mathrm{m})$ long respectively; they are the most abundant ossicles and are located in the tubular wall of the podia, arranged in whorls of 3 or 4 ossicles, each whorl fitting telescopically with the blunt spines upwards (Fig. $7 \mathrm{~g}-\mathrm{i}$ ).The fourth type of ossicles has the appearance of small circular plates, with large and small holes, and with short blunt spines on all margins (Fig. 7e). Unlike the other types, they are larger and have a very smooth curvature, with a length varying from 75 to $116 \mu \mathrm{m}(\bar{x}: 90.4 \mu \mathrm{m})$, and they are located at the base of the tubular wall of the podia (Fig. 7h, i).

In addition, in the preparations of ossicles of the dorsal podia, 9 ossicles of a different type were found, 7 in the shape of a long, narrow and flat rod, mostly with 3-5 small holes aligned (Fig. 7fl) and another 2 ossicles of greater width and more holes (Fig. 7f2), whose length varied from 102 to $142 \mu \mathrm{m}(\bar{x}: 117.3 \mu \mathrm{m})$. It was impossible to determine the location of these ossicles on the podium, ruling out contamination during the removal of the dorsal podia, since they were cut one by one at their base flush with the dorsal plate ossicles. The 5 anal podia have the same ossicles and structure as the dorsal podia (Fig. 7k).

Ossicles of the tentacles and introvert The tentacles are contractile, long, digitiform in extension and conical in contraction, and are provided with various types of ossicles (Fig. 8u). The most abundant and identifying are the long, thin, evenly thick, arched ossicles, which represent $70 \%$ of the ossicles of the tentacle (Figs. 8b). Most of these ossicles show two short apophyses in the middle area on the outside of the arch, with the end forked or with a dilation with a small hole, although the larger ossicles have three or four apophyses. In addition, they have a perforated dilation with 2 to 5 small holes on both ends of the arch. The arched ossicles have a wide range of sizes, with a length of 96-225 $\mu \mathrm{m}(\bar{x}: 163.2 \mu \mathrm{m})$, with an 


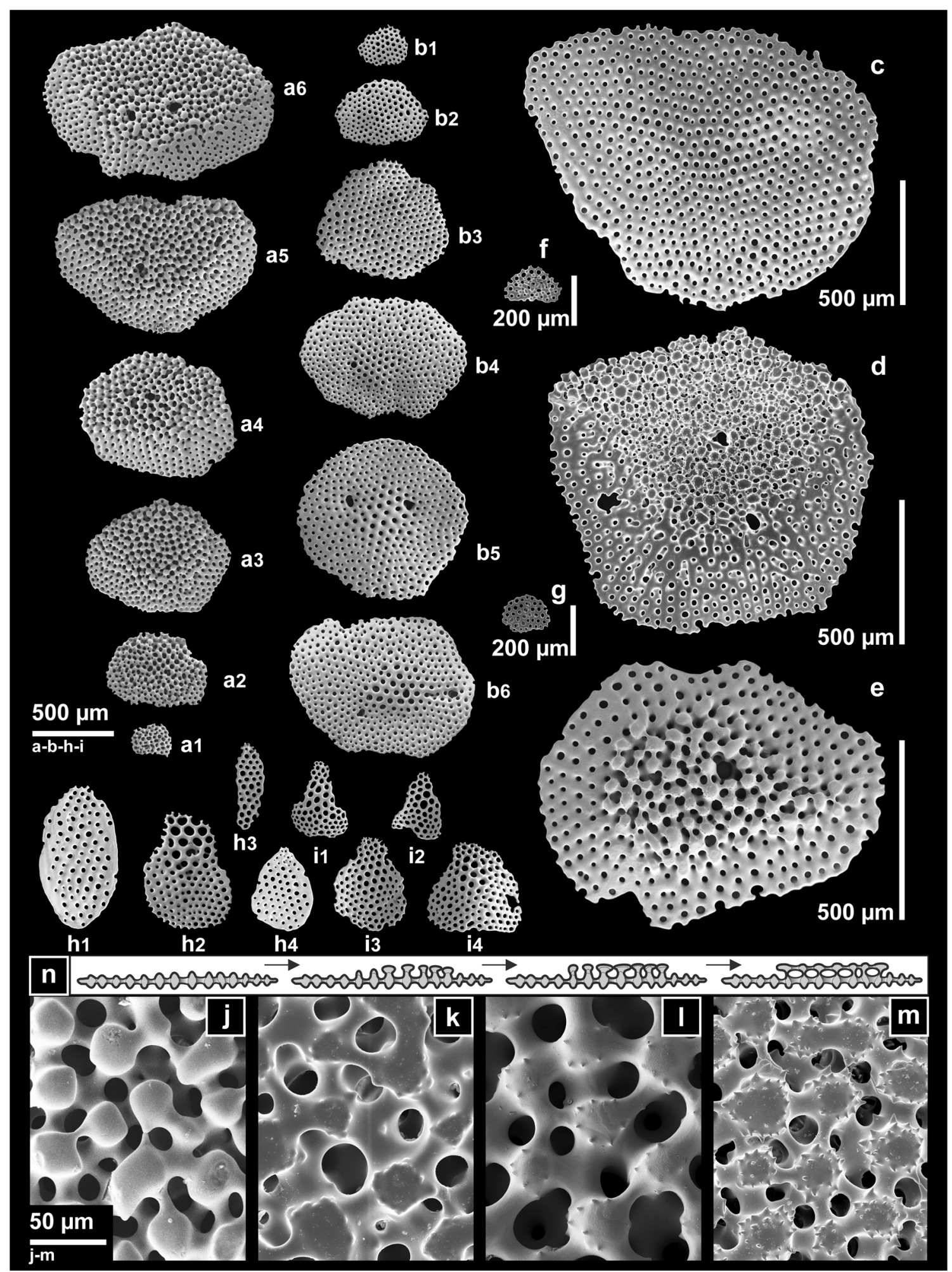

Fig. 4 Psolidium bathygalego nom. nov. SEM images of the dorsal plates and the oral and anal cone plates. a Dorsal view and $\mathbf{b}$ ventral view, of the sequence of dorsal plates from the margin to the dorsal midline; $\mathbf{c}$ Large dorsal plate in ventral view; $\mathbf{d}$ Large dorsal plate in dorsal view; e Large

oblique disposition along the entire digitiform tentacle (Fig. 3d). Depending on their apical, middle or basal position, middorsal plate in dorsal view; $\mathbf{f}, \mathbf{g}$ Very small dorsal plates in dorsal and ventral view; $\mathbf{h}$ Oral cone plates; $\mathbf{i}$ Anal cone plates; $\mathbf{j}-\mathbf{m}$ Different external ornamentation of the dorsal plates; $\mathbf{n}$ Pattern of the formation and growth of the dorsal plates

this causes different degrees of curvature and size of the ossicle, with the most apical ones being very small $(73-85 \mu \mathrm{m})$ 

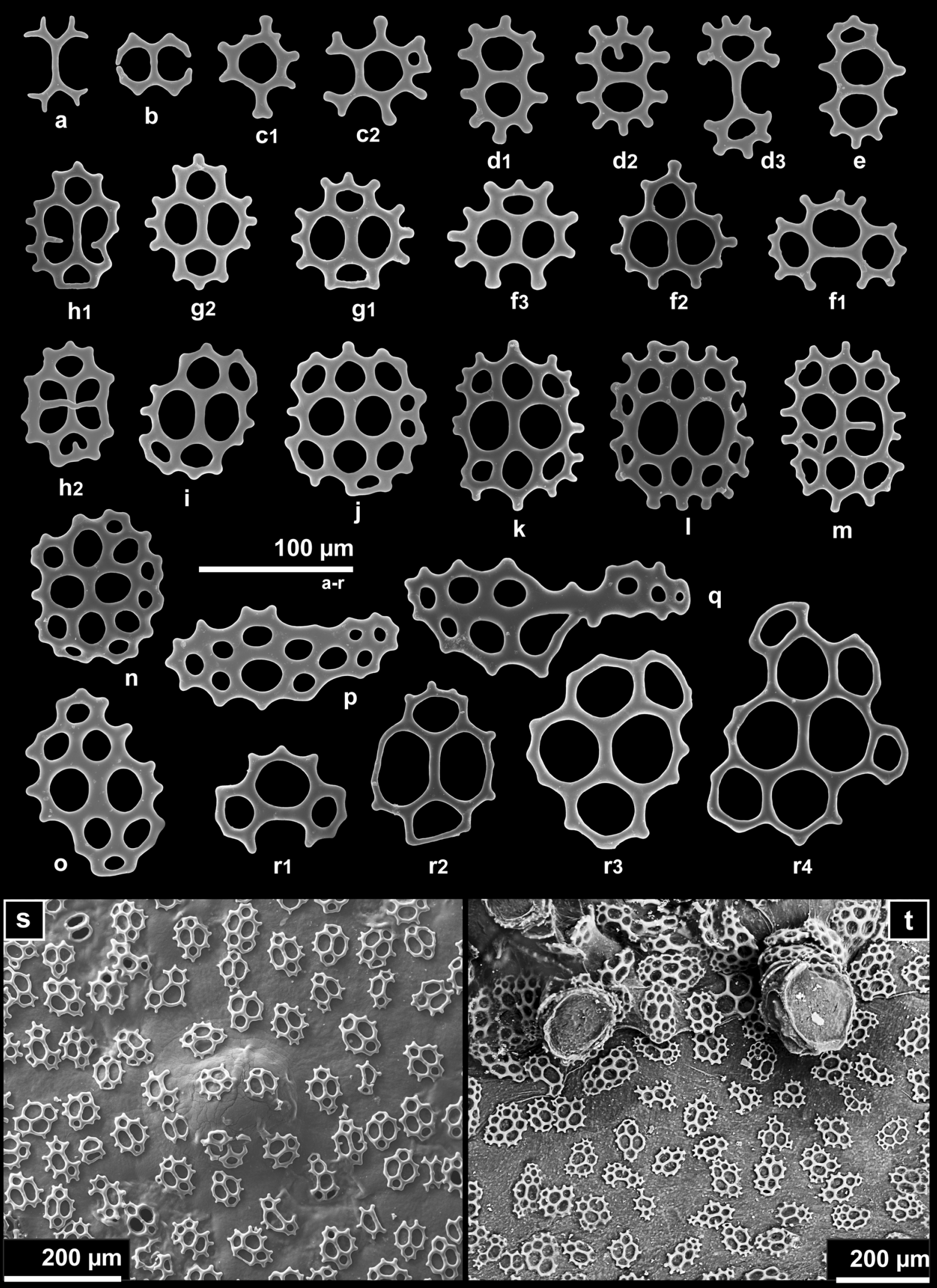

Fig. 5 Psolidium bathygalego nom. nov. SEM images of ossicles of the ventral sole. a-r Different types and sizes of ossicles; $\mathbf{s}$ Distribution of the ossicles in the central area of the ventral sole; $\mathbf{t}$ Distribution of the ossicles around the base of the ventral perimeter podia 
and having a very closed curvature (Fig. 8b1-b3). At the apical end of the tentacle, tiny cruciform ossicles were observed in a plate measuring $69 \times 69 \mu \mathrm{m}$ to $75 \times 70 \mu \mathrm{m}$, with four large holes in a crossed arrangement and one or two small holes at the ends with small apophyses (Figs. 8a). These ossicles could be homologous to the apical terminal plates of the dorsal podia and the ventral perimeter podia. In the basal area of the tentacles, there are some rod-shaped ossicles, almost straight, robust, and mostly perforated in the central area, with the ends dilated showing small holes and short apophyses (Figs. 8c). They are 155-235 $\mu \mathrm{m}(\bar{x}$ : $200.3 \mu \mathrm{m})$ long, similar to the largest arched ossicles and constitute $20 \%$ of the ossicles of the tentacle. When the tentacle is fully extended, it is very narrow and similar in diameter throughout, except at the apex. The ossicles can be observed in an oblique dystic disposition, with the small apophyses directed towards the apex.

The introvert is well developed and, when protruded, allows the crown of tentacles to be widely separated from the body (Fig. 2a). The introvert is reinforced by numerous and scattered ossicles, rounded, oval, and elongated, which also surround the mouth and the base of the tentacles (Fig. 8d-m). The most abundant (57\%) and longest (137-245 $\mu \mathrm{m})$ are the elongated ones, followed by the oval ones $(27 \%)$ of shorter length $(142-193 \mu \mathrm{m})$ and the most scarce $(16 \%)$ the small rounded ones $(91-151 \mu \mathrm{m})$. All show large holes, generally central, and small holes at the ends, with blunt or pointed apophyses around the contour of the ossicle, presenting nodes, more or less patent and numerous in $50 \%$ of the ossicles (Fig. 8d, g, k, m).

\section{Internal anatomy}

Introvert, calcareous ring, and retracting muscles The introvert and the oral tentacles are closely connected and are only externally visible when protruded (Fig. 2a). Together, they are retracted into the body by the contraction of the longitudinal retracting muscles inserted into the calcareous ring, being enclosed by the ossicles of the oral cone. The tentacles are housed over the calcareous ring and the introvert folded over them, under the plates of the oral cone (Fig. 11s). The external epithelium of the tentacles, provided with numerous ossicles, covers the epithelium of the tentacular podium of the watervascular system, but does not cover the tentacular ampullae. The external epithelium of the tentacles continues with the epithelium of the oral membrane and that of the introvert, and when this set is completely protruded, it is very thin and semitransparent, protruding from the margin of the oral cone plates (Fig. 2a). The coelomic cavity of the introvert communicates with the main coelom outside the calcareous ring.

The pharynx is surrounded by a ring of calcareous plates, the calcareous ring, which supports the pharynx and the ring canal of the water-vascular system by means of the pharyngeal suspensors. The longitudinal retracting muscles are inserted into the calcareous ring. It is made up of ten robust pieces, five radial and five interradial, of similar size and inverted $Y$ shape, with two wide basal divergent branches and a longer upper projection (Fig. 8n-t). The pieces are assembled on the side of their basal parts, forming a closed crown with the projections of each piece directed upwards (Fig. 9f). All the pieces of the calcareous ring have a semi-circular basal notch, more or less wide in different specimens; the anterior projections, although of the same length, are different in the radial and interradial pieces. In the interradial pieces, the anterior projections are triangular, narrow, and tapering (Fig. 8n-p), while in the radial pieces, the anterior projections are rectangular, wider, and with an indentation in the distal third, which shapes their forked end (Fig. 8q, r); some radial pieces lack an indentation or have a joined end (Fig. 8s, t). The longitudinal retracting muscles are inserted on the anterior external surface of the anterior projections of the radial pieces (Fig. 10h), whereas the pharynx suspensors are inserted on the internal surface of the calcareous ring. The calcareous ring, the tentacle ampullae, the ring canal, and the epithelium of the oral face enclose a coelomic cavity adjacent to the pharynx, the peripharyngeal sinus, although it is not completely closed as it communicates through lower spaces with the main coelom.

The longitudinal retracting musculature is formed by five long muscular fascicles, arranged in a radial position (A, B, C, $\mathrm{D}$, and $\mathrm{E}$ ) and which have their origin in the external face of the apical notch of the anterior projection of the calcareous ring radial pieces (Fig. 10f, h). There are two dorsal-lateral muscles (radii $\mathrm{C}$ and $\mathrm{D}$ ), two ventro-lateral muscles (radii $\mathrm{B}$ and E), and one mid-ventral muscle (radius A) (Fig. 10b, e-g). All are of flattened section except the one in radial position A which is of circular section. Unlike the radial canals of the water-vascular system, their arrangement is straight and they are inserted into the corresponding radial canal at different distances, which determines different lengths (Fig. 10f). Thus, the retracting muscle of radius $\mathrm{A}$ is the shortest, with an almost vertical disposition; it is inserted in the radial canal A with an angle of $50^{\circ}$, at a very short distance from the anterior margin of the animal, more or less $10 \%$ of the length of the sole (Fig. 10f, j). The retracting muscles of the radii B and $\mathrm{E}$ are of medium length, with a more oblique disposition, inserted in the corresponding radial canals $\mathrm{B}$ and $\mathrm{E}$ with an angle of $24^{\circ}$ and at $1 / 3$ of the length of the sole (Fig. 10f, k). The retracting muscles of radii $\mathrm{C}$ and $\mathrm{D}$ are the longest, with a very oblique arrangement, inserted into the corresponding radial canals $\mathrm{C}$ and $\mathrm{D}$ at an angle of $8^{\circ}$ and at $2 / 3$ of the sole length (Fig. 10f). The arrangement and different lengths of the retracting muscles are the most suitable for retraction of the calcareous ring, due to the oblique dorsal-anterior position of the oral cone (Fig. 10f).

When the retracting muscles are fully contracted, those of radii $\mathrm{B}$ and $\mathrm{E}$ are arranged in a cross, perpendicular to the sides of the animal (Fig. 11s), so that the calcareous ring is at their 


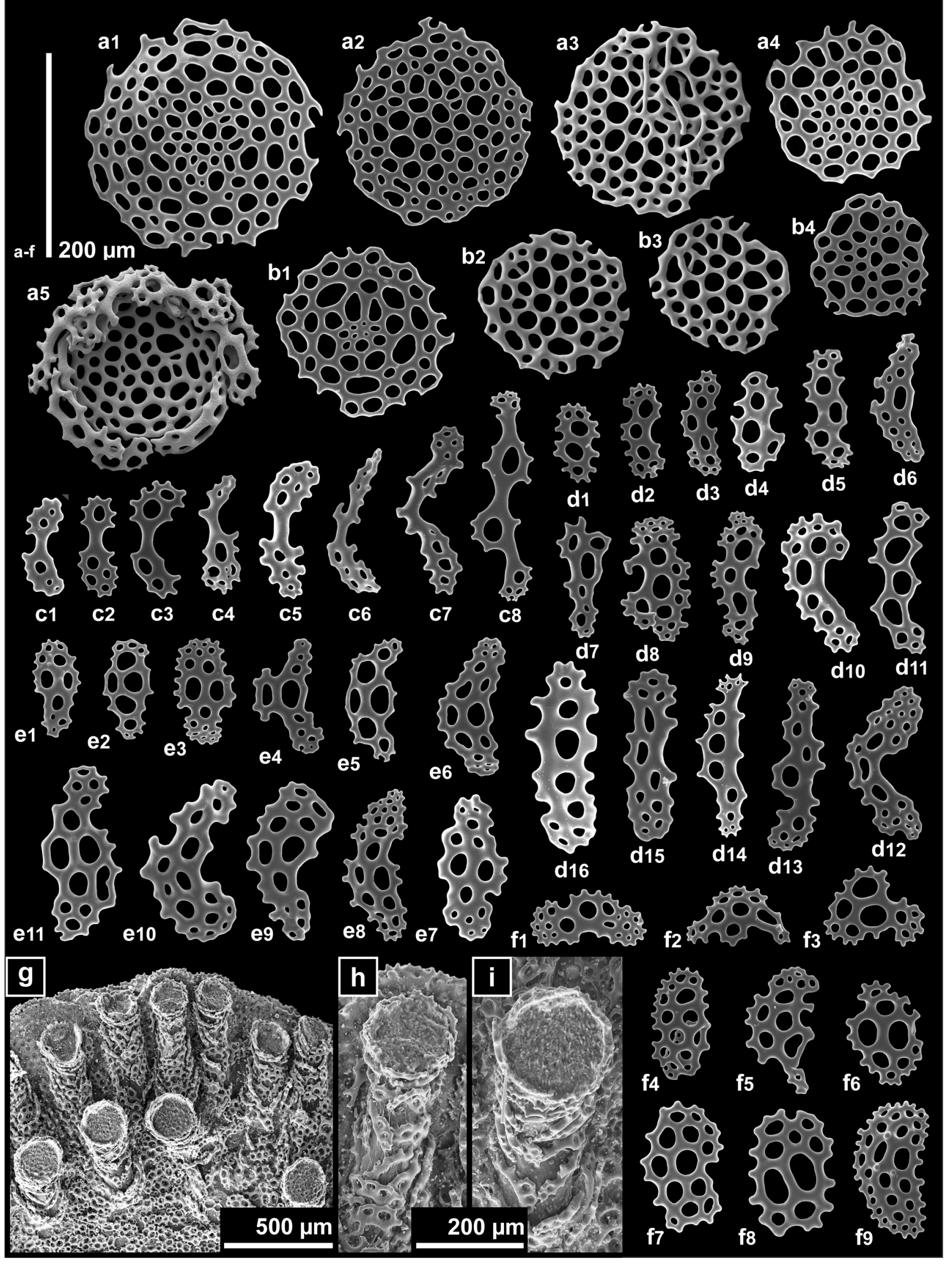


4 Fig. 6 Psolidium bathygalego nom. nov. SEM images of ossicles of the ventral perimeter podia. a Different types and sizes of the apical plate of the podia of the internal perimeter row; $\mathbf{b}$ Different types and sizes of the apical plate of the podia of the external perimeter row; $\mathbf{c}-\mathbf{f}$ Different types and sizes of the ossicles of the perimeter podia; $g$ Detail of the ventral perimeter podia; h External ventral perimeter podium; i Internal ventral perimeter podium

height, and thus the introvert and oral membranes acquire a funnel shape with the tentacles inside (Figs. $3 \mathrm{j}$ and $11 \mathrm{~s}$ ). In this state of maximum contraction of the longitudinal retractor muscles B, C, D and E, $50 \%$ of their distal end is very wide, at their insertion into the corresponding radial canal (Fig. 11s).

The pharynx, located in the center of the calcareous ring, is supported by numerous pharynx suspensors which are arranged radially from its external surface to the internal faces of the calcareous ring and the epithelium of the tentacle ampullae (Fig. 9e). The rectum or cloaca is supported by numerous cloacal suspensory muscles that surround it, arranged radially along its entire length and inserted and attached to the internal wall of the surrounding body and some to the ventral sole (Fig. 9g).

Water-vascular system The water-vascular system of Psolidium bathygalego nom. nov. comprises a ring canal that surrounds the lower part of the pharynx and has as appendages a Polian vesicle and a stone canal. Five radial canals are distributed from the ring canal to the anal end; along their length they present branches to the external podia that have different functions: oral, anal, dorsal, and ventral-perimetral (Fig. 10c).

The ring canal is located around the inferior area of the pharynx at its junction with the esophagus and is arranged transversely at the height of the inferior margin of the calcareous ring (Fig. 10a). The ring canal is pentagonal at its external margin, since five wide canals emerge from it in a radial position extending to the inferior margin of the calcareous ring (Fig. 10b). A single large and pyriform Polian vesicle emerges from the ring canal in the position of the interradius ED; its shape ranges from elongated to spherical (Fig. 10a, b, g). In the position of the interradius CD a thin, short, stony canal emerges very close to the esophagus (Fig. 10a) under the gonoduct. Its end shows a slight dilation, whose shape or appearance could not be observed.

Each oral tentacle bears a tentacular ampulla at its internal basal area which communicates with the ring canal. The tentacle ampullae occupy all the space between the anterior projections of two consecutive pieces of the calcareous ring (Fig. 10a, $h, i)$. The two tentacular ampullae on both sides of each radial piece of the calcareous ring, which correspond to the same pair of oral tentacles, have, in the inferior lateral area close to the anterior projections of the radial piece, a small orifice that communicates through a short duct with the ring canal.

The radial canals that emerge from the ring canal extend below the calcareous ring and rise on the external face of each radial piece, to a little above the tentacular ampullae (Fig.10h, i). From there they descend, adhering to the body wall, to the anal cone. The radial canals are double throughout (Fig. 10g) and have a different arrangement. The radial canal A descends almost vertically through the anterior body wall to the ventral sole; it continues medially through the sole to the posterior end, from where it rises through the body wall, to the anal cone, topped by an anal podium (Fig. 10c-e, g, j). The radial canal A is double throughout its length, and it is the only one lacking podia, except the anal podium and the two oral bifid tentacles.

The radial canals, $\mathrm{B}$ and $\mathrm{E}$, descend slightly oblique forwards along the antero-lateral body wall to the anterior margin of the ventral sole, the radial canal B on the right side and $E$ on the left (Fig. 10c). At this point they are divided into two branches (Fig. 10e, j), an anterior branch that circles the margin of the sole to the radial canal A, to which the two branches of the radial canals B and $\mathrm{E}$ are joined, thus forming an anterior arch that circles the sole. The other branch of the radial canals $\mathrm{B}$ and $\mathrm{E}$ is directed towards the posterior area, each one along the margin of the ventral sole up to the height of the anal cone where canals $\mathrm{B}$ and $\mathrm{E}$ bifurcate again into two branches (Fig. 10d). One branch ascends to the anal cone ending in the anal podia $\mathrm{B}$ and $\mathrm{E}$, while the other branch, $\mathrm{B}$ and $\mathrm{E}$, continues along the margin of the sole until it joins canal $\mathrm{A}$, forming here too a posterior arch that surrounds the sole (Fig. 10d). In this way, the radial canals $\mathrm{B}$ and $\mathrm{E}$ are arranged in an oval that surrounds the entire sole (Fig. 10c) and from which all the ventral tubular podia emerge (Fig. 10k).

The radial canals $\mathrm{C}$ and $\mathrm{D}$ of the bivium descend slightly down the oral cone, running along the body wall of the upper middle dorsal area and at the back ascending towards the anal cone, with each radial canal ending at the anal podia $\mathrm{C}$ and $\mathrm{D}$ (Fig. 10c, g). The radial canals $\mathrm{C}$ and D present no apparent ramification along their entire length, but it has to be considered that small canals should emerge from them in order to communicate with the numerous dorsal podia scattered along the back, although they have not been observed. In two specimens an irregular reticulation was observed by dissection all over the back under the plates, where the position of the dorsal podia coincided (Fig. 11t), but it is not certain that it could correspond with the small canals of the dorsal podia. All the podia of the water-vascular system of Psolidium bathygalego nom. nov. end in an expansion in the shape of a sucker, except the oral and anal podia.

Digestive system The mouth opens at the center of the oral membrane, surrounded by 10 oral tentacles, and provided with a ring sphincter. It continues in a postero-ventral direction through a bulbous pharynx with thick and muscular walls, located in the center of the calcareous ring and supported by numerous pharynx suspensors, which are arranged radially from the surface of the pharynx to the internal faces of the calcareous ring and the epithelium of the tentacle ampullae (Fig. 9e). 


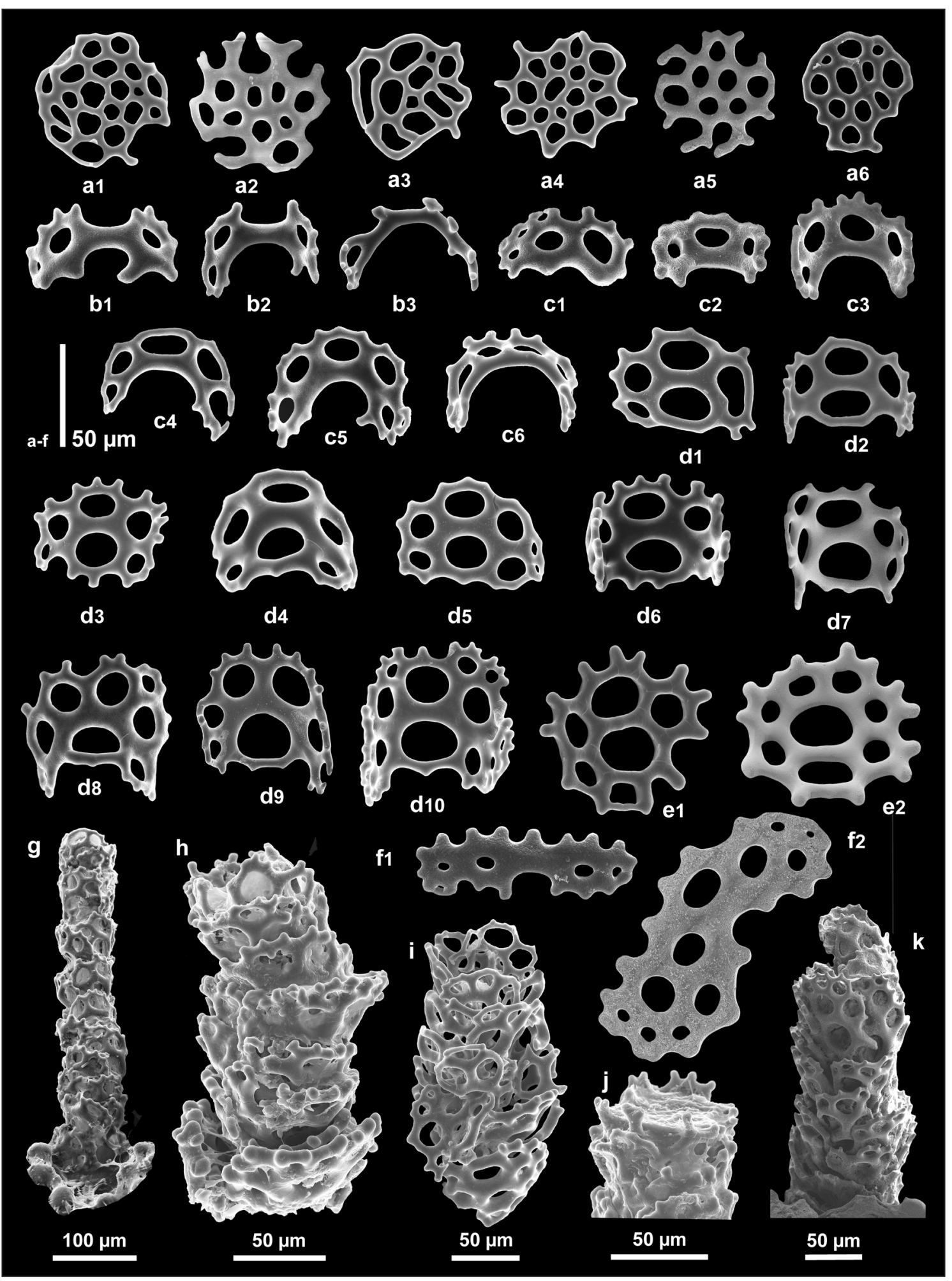

Fig. 7 Psolidium bathygalego nom. nov. SEM images of ossicles of the dorsal podia. a Different types and sizes of the apical plate of the podium; b-f Different types and sizes of the ossicles of the dorsal podia; $\mathbf{g}$

The pharynx continues with a straight, muscular, tubular esophagus of uniform diameter, whose external surface is smooth and its internal surface shows many small folds. The
Complete dorsal podium; $\mathbf{h}$ Basal section of the podium; i Middle section of the podium; $\mathbf{j}$ Apical section of the podium; $\mathbf{k}$ Anal podium

esophagus extends in a posterior direction, supported by the dorsal mesentery CD, along the first third of the animal (Fig. 9e, j, p). After the esophagus, the diameter of the 


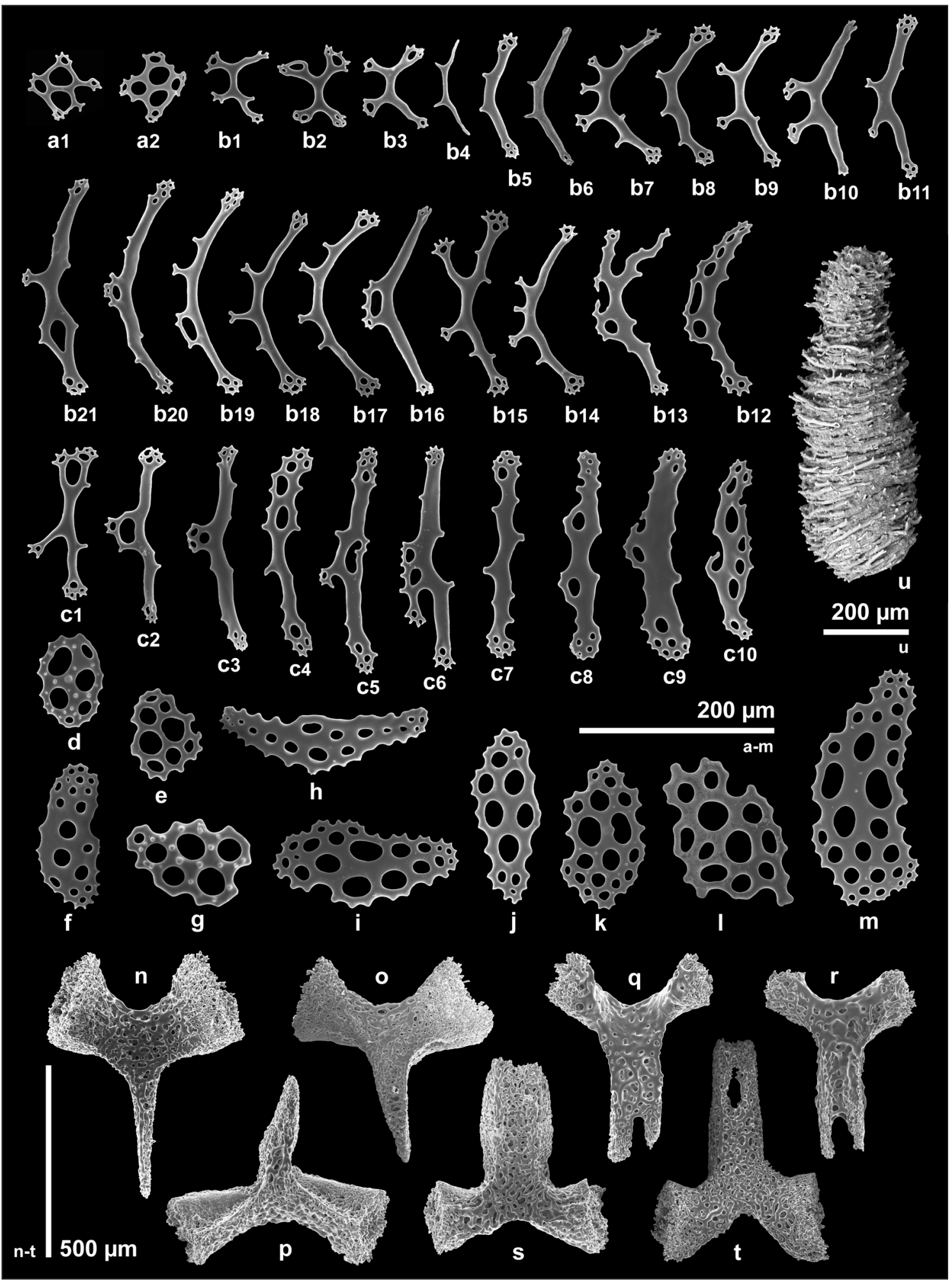

Fig. 8 Psolidium bathygalego nom. nov. SEM images of the ossicles of the oral tentacles, introvert and calcareous ring. a-c Different types and sizes of the ossicles of the oral tentacles; $\mathbf{d}-\mathbf{m}$ Different types and sizes of

the ossicles around the base of the oral tentacles and introvert; $\mathbf{n}-\mathbf{p}$ Interradial pieces of the calcareous ring; q-t Radial pieces of the calcareous ring; $\mathbf{u}$ Structure of a contracted oral tentacle

digestive tube increases widely where the stomach begins. This shows a uniform diameter throughout its length, also supported by the dorsal mesentery $\mathrm{CD}$ and ending near the posterior third of the animal (Fig. 9h, k, p). After the stomach, a slight narrowing indicates the beginning of a long intestine, which has 4 sections, 2 ascending and 2 descending (Fig. 9h, 


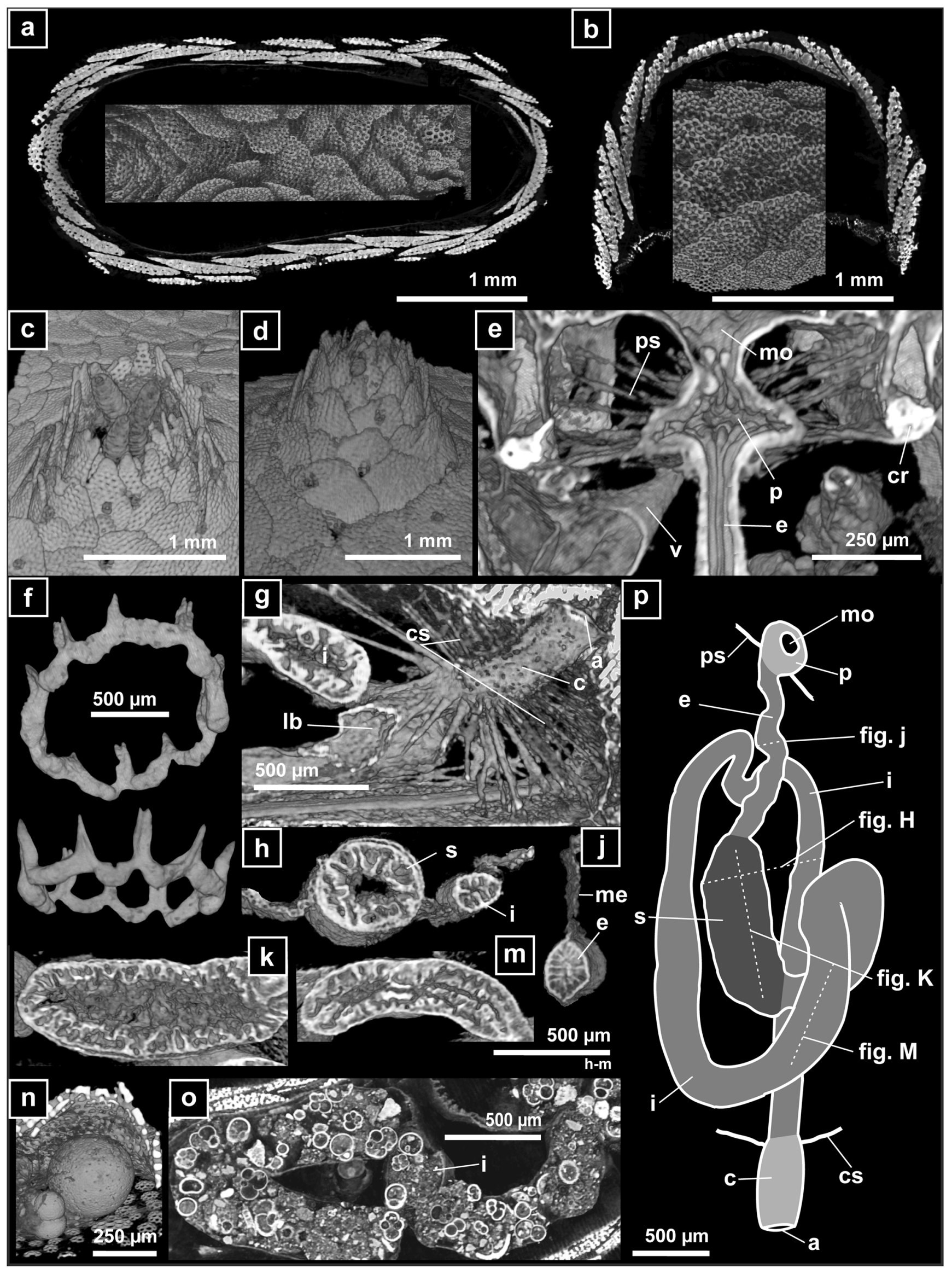


Fig. 9 Psolidium bathygalego nom. nov. a Frontal section of the overlapping of the dorsal plates at the lower level and medial plates between the oral and anal cones; b Transverse section of the overlapping of the dorsal plates at mid-body level and lateral view; c Arrangement of the oral cone plates surrounding the tentacles; d Arrangement of the anal cone plates; e Longitudinal section of the anterior part of the digestive tract; $\mathbf{f}$ Calcareous ring in inferior and lateral view; $\mathbf{g}$ Longitudinal section of the posterior part of the digestive tract; $\mathbf{h}$ Transverse section of the stomach and intestine; $\mathbf{j}$ Transverse section of the esophagus; k Longitudinal section of the stomach; m Longitudinal section of the intestine; $\mathbf{n}$ Large Foraminifera under the anal cone; $\mathbf{o}$ Gastric repletion in the intestine; $\mathbf{p}$ Schematic drawing of the regionalization of the digestive system. (a-o Micro-CT; except c-d SEM)

$\mathrm{m}, \mathrm{p})$. It begins by forming a loop on the right side, with a first ascending section of the intestine, of smaller diameter, which continues forwards along the interradius $\mathrm{AB}$ in a short section. Again an intestinal loop is formed originating a second descending section of the intestine which is directed towards the posterior area along the interradius $\mathrm{BC}$, curving widely at the height of the posterior quarter of the animal after the stomach, forming the third ascending section which is directed towards the anterior area along the interradius DE, supported by the left mesentery. It then crosses to the right under the medial length of the esophagus, forming the fourth descending section of the intestine, the longest one, which goes towards the posterior area, running all its length along the interradius $\mathrm{AB}$, supported by the ventral mesentery, until it opens through a small atrium, in the rectum or cloaca, where it meets the beginning of the respiratory trees (Fig. 9g, p). The rectum or cloaca is a wide, muscular, cylindrical tube supported by numerous suspensory muscles, arranged radially and inserted into the internal wall of the body and some into the ventral sole. Its posterior end ends in the anus, provided with a muscular sphincter that opens to the outside in the center of the anal cone (Fig. 9g, p).

This arrangement of the digestive tract is clearly observed in many specimens, but in others, after the descending section of the mouth, pharynx, esophagus, and stomach, the intestine is arranged in two sections, an ascending section on the left side of the stomach, which anteriorly forms a loop under the esophagus, which continues along a long descending intestinal section to the rectum (Fig. 11a, d). The difference between these arrangements of the digestive tract is the appearance on the right, of an extra loop with two short intestinal sections behind the stomach (Fig. 9p and 11b,c) that in some specimens is minimally outlined as an arch towards the front. These two arrangements of the digestive tract are independent of the degree of repletion it presents.

In those specimens in which the degree of repletion is high throughout its length (Fig. 9n, o), it is impossible to discern the different parts described above (vide supra). The limits between the esophagus, stomach, and intestine are indistinguishable, but the intestine may be arranged in only two or four sections. In certain specimens that present an extreme degree of repletion, the digestive tract may occupy practically the entire visceral cavity (Fig. 11d), displacing the calcareous ring forwards and the gonad laterally. In Fig. 11a-d, it can be seen that the volume of the digestive tract is independent of whether the intestine has two (Fig. 11a, d) or four sections (Fig. 11b, c), since its volume depends on the degree of repletion. It should be noted in Fig. 9o that most of the digestive contents are foraminifera, some of which are voluminous and of extraordinary diameter, such as the specimen of Sphaerogypsina globulus (Reuss 1848), in Fig. 9n, housed under the anal cone.

Respiratory trees The respiratory system of Psolidium bathygalego nom. nov. is formed by a pair of respiratory trees that start in the antero-lateral part of the cloaca, bifurcating into two branches, one to the right and the other to the left of the cloaca. Both branches of the respiratory tree are two thin-walled tubes, little branched, of circular section which run laterally through the coelom; the right branch is the longest and always extends up to the height of the esophagus, and the left branch, the shortest, never goes beyond the stomach (Fig. $11 \mathrm{~h}, \mathrm{n}-\mathrm{q}$ ).

The left branch of the respiratory tree, after a short stretch, bifurcates into two sub-branches, a dorsal and a ventral one. The dorsal sub-branch, of short length, has two or three small branches and ascends towards the back running forwards in a radial position $\mathrm{D}$. The ventral sub-branch, a little longer, also with two or four branches, runs through the ventral sole in a radial position $\mathrm{E}$, always to the left of the final section of the intestine and surrounded by different loops of the digestive system. The left branch and sub-branches present a somewhat variable length in the specimens studied, from short (Fig. 11np) to medium (Fig. 11q), but always shorter than the right branch of the respiratory tree.

The right branch of the respiratory tree bifurcates, almost initially, into two sub-branches, dorsal and ventral, which run forwards in radial positions $\mathrm{C}$ and $\mathrm{B}$. The ventral sub-branch is always short, being the shortest branch of the tree. The dorsal sub-branch shows small branches and a similar diameter throughout its length; it always has a wide final expansion with a short, very narrow sub-branch. The dorsal sub-branch reaches the anterior part of the esophagus, as can be seen in Fig. $11 \mathrm{~h}$, whose respiratory tree corresponds to the pattern in Fig. 11o. The right branch is attached to the wall of the body by mesenteric connectives, while the left branch is largely arranged between the digestive loops. The branches and subbranches of the respiratory trees are completely covered with numerous small, rounded, thin-walled, and pyriform vesicles (Fig. 11r); their diameter ranges from 2.5 to $10.5 \mu \mathrm{m}$, although most are between 6.1 and $8.1 \mu \mathrm{m}$.

In addition, the respiratory trees have numerous ossicles under the epithelium, ranging in size from 28.5 to $136.5 \mu \mathrm{m}$ in length and 18 to $91 \mu \mathrm{m}$ in width (Fig. 12d-f), although 


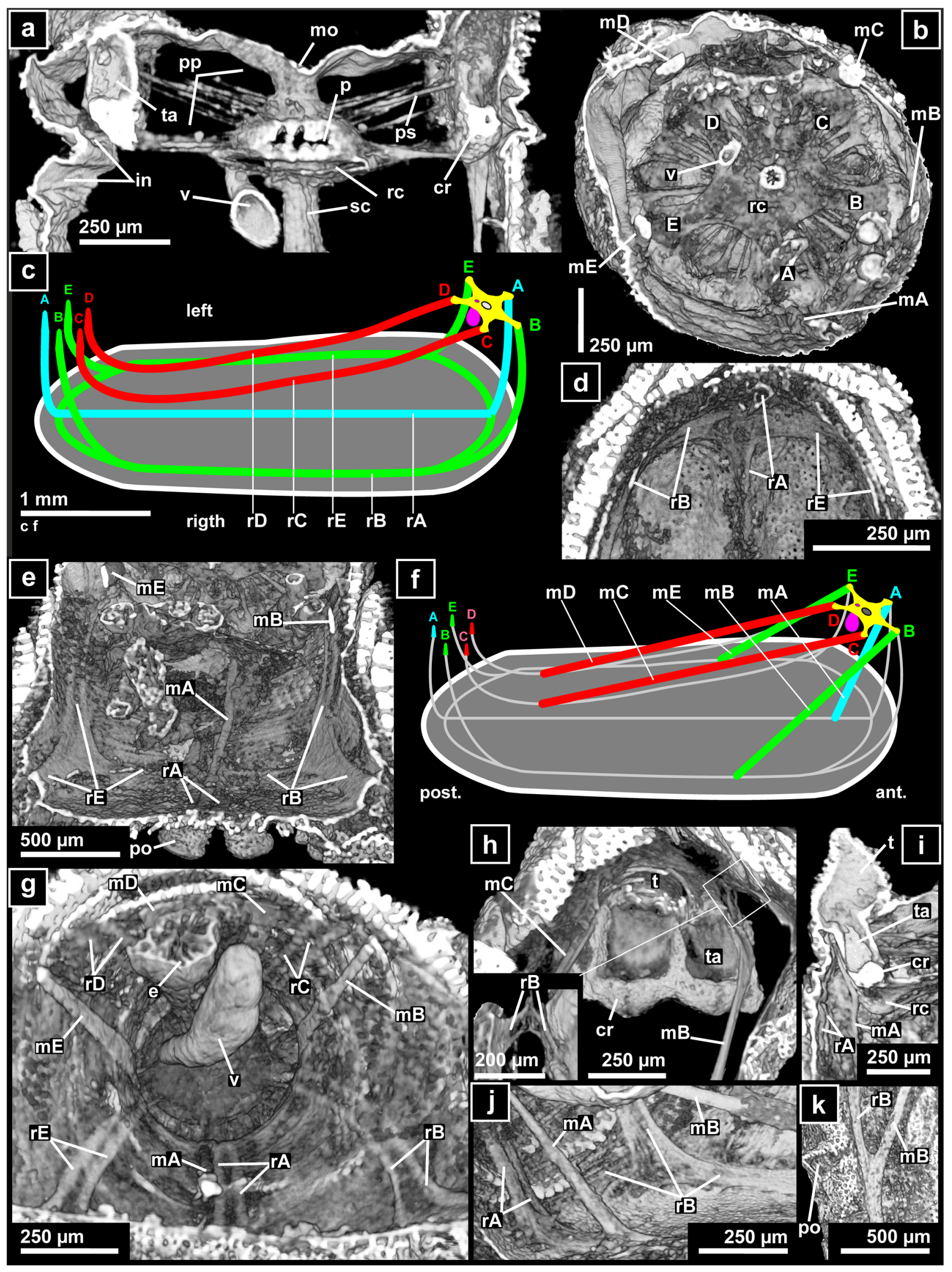


4 Fig. 10 Psolidium bathygalego nom. nov. Micro-CT images of watervascular system and retractor muscles. a Longitudinal section of the anterior part showing the ring canal, Polian vesicle, and stone canal; b Posterior view of the ring canal and arrangement of the 5 radial longitudinal retractor muscles; c Schematic drawing of the water-vascular system; d Posterior confluence of the radial canals of the trivium: A-B-E; $\mathbf{e}$ Arrangement and anterior confluence of the radial canals of the trivium: A-B-E and radial longitudinal retractor muscles: A-B-E; f Schematic drawing of the radial longitudinal retractor muscles; $\mathbf{g}$ Arrangement after the calcareous ring of the five radial canals and longitudinal retractor muscles; $\mathbf{h}$ Union of the radial B canal arising from the ring canal with radial canal B running backwards attached to the body wall and insertion in the calcareous ring of the radial longitudinal retractor muscles $\mathrm{B}$ and $\mathrm{C}$; i Tentacle, tentacular ampullae, retractor muscle $\mathrm{A}$, and radial canal $\mathrm{A} ; \mathbf{j}$ Radial canals $\mathrm{A}$ and $\mathrm{B}$ and radial retractor muscles $\mathrm{A}$ and $\mathrm{B} ; \mathbf{k}$ Posterior end of the longitudinal retractor muscle $\mathrm{C}$ in radial canal $\mathrm{C}$

most are between 58 and $100 \mu \mathrm{m}$ in length and 35-60 $\mu \mathrm{m}$ in width. In general, they are X-shaped (Fig. 12d), with a small central bar, the ends of which bifurcate at angles between $50^{\circ}$ (Fig. 12d14) and $100^{\circ}$ (Fig. 12d23). In the larger ossicles, the $\mathrm{X}$-arms bifurcate (Fig. 12d1-d13) giving it a more spiny appearance. The length-to-width ratio ranges from 1 (Fig. 12d24) to 3.2 (Fig. 12d7), but most are between 1.4 and 2. Although the shape and size are quite similar to the ossicles of the gonadal tubules (Fig. 12a-c), the ossicles of the respiratory trees are thornier and much more abundant (Fig. 12e). As can be seen in Fig. 12f, they cover, under the epithelium, the entire surface, including the wall of the cloaca, so they may play a structural and defensive role.

Reproductive system Psolidium bathygalego nom. nov. has the sexes separated, dioecious, and does not present any secondary sexual dimorphism that allows differentiating externally males and females. However, due to the very fine tegument of the ventral sole, almost transparent, the viscera of the general body cavity can be seen in most specimens, and it is possible to distinguish whether the gonad is male or female (Fig. 11g, h).

Males and females have a single fasciculated gonad, located in the interradius CD dorsally to the esophagus, which extends towards the posterior area freely through the coelom, forming a bundle of gonadal tubules to the right and left of the dorsal mesentery CD (Fig. 11i). All gonadal tubules are basally joined, opening to a common genital base, from which a short, narrow, cylindrical gonoduct extends forward through the mesentery CD. The gonoduct ascends on the exterior area of the calcareous ring (Fig. 11i) and opens into a gonopore located on the middorsal line, between the oral tentacles of the interradius CD (Fig. 3a); the existence of a genital papilla has not been observed.

The gonad is made up of genital caeca long tubular, cylindrical, claviform or moniliform, but never branched. The gonadal tubules of females (Fig. 11f, h, i) are claviform when the oocytes are barely developed (Fig. 11k), but they are moniliform when the oocytes are large, as the diameter of the gonadal tubules increases in the areas corresponding to the oocytes (Fig. 11h, 1). They are shorter than the gonadal tubules of the males and are arranged, without an apparent order, on the coelom of the anterior half of the body, interspersed between the rest of the viscera. The gonadal tubules of the males are cylindrical, of more uniform diameter, longer than those of the females and are arranged, also without an apparent order between the viscera, on the coelom of the entire body cavity (Fig. 11e, g, j).

When the gonadal tubules of both males and females are observed under OM, the presence of small ossicles (Fig. 12ac), mostly in the form of a more or less elongated X, is appreciated subepithelially in both gonadal tubules, and in smaller numbers, there are monoaxon ossicles. The radii of the $\mathrm{X}$ can be equal or of different lengths, straight or curved, smooth or provided with blunt spines or small tubercles (Fig. 12a). The $\mathrm{X}$-shaped ossicles are 41.1 to $249.3 \mu \mathrm{m}$ long and 15.3 to $71.1 \mu \mathrm{m}$ wide, but most are 85 to $160 \mu \mathrm{m}$ long and 25 to $50 \mu \mathrm{m}$ wide, with a highly variable length/width ratio ranging from 1.9 (Fig. 12a12) to 6.1 (Fig. 12a4). The monoaxon ossicles are much less numerous and may be straight (Fig. 12a18) or slightly curved (Fig. 12a17) with a length between $156.1 \mu \mathrm{m}$ (Fig. 12a17) and $210.3 \mu \mathrm{m}$ (Fig. 12a18) and a thickness of 3.9 to $6.4 \mu \mathrm{m}$. They appear to be centrally articulated, but this has not been accurately verified. The number of ossicles in each gonadal tubule is very variable, from 3 to 4 to almost twenty, being more numerous in the gonadal tubules of males (Fig. 12c) than in those of females (Fig. 12b). Compared to the ossicles of the respiratory trees, they are much less numerous, somewhat larger and with fewer branches.

In the specimens in which the gonad could be seen due to the transparency of the sole, the number of males and females was counted in 222 specimens, resulting in 146 females $(66 \%)$ and 76 males (34\%), so that the number of females doubles that of males. Also, it was found that the specimens of less than $6 \mathrm{~mm}$ in length did not yet have the gonad formed and a specimen of $6.5 \mathrm{~mm}$ in length had only two gonadal tubules. The number of gonadal tubules in males and females is variable. Thus, 10 specimens of each sex were counted and the number of gonadal tubules varied between 5 and 14 in both sexes. Likewise, in a female with 13 gonadal tubules, with well-developed oocytes, there were 16, 21, 21, 26, 26, 27 , $27,30,31,32,32$, and 39 oocytes respectively in each gonadal tubule.

The length and width of 110 oocytes were measured. Those that were in well-developed gonadal tubules (Fig. 111) had a length between 148 and $205 \mu \mathrm{m}$ and a width between 110 and $177 \mu \mathrm{m}$; some were almost spherical $(153 \times 150 \mu \mathrm{m})$, but most were oval $(186 \times 141 \mu \mathrm{m})$ (Fig. 111). In the moderately developed gonadal tubules (Fig. $11 \mathrm{~m}$ ), there was a wide range 


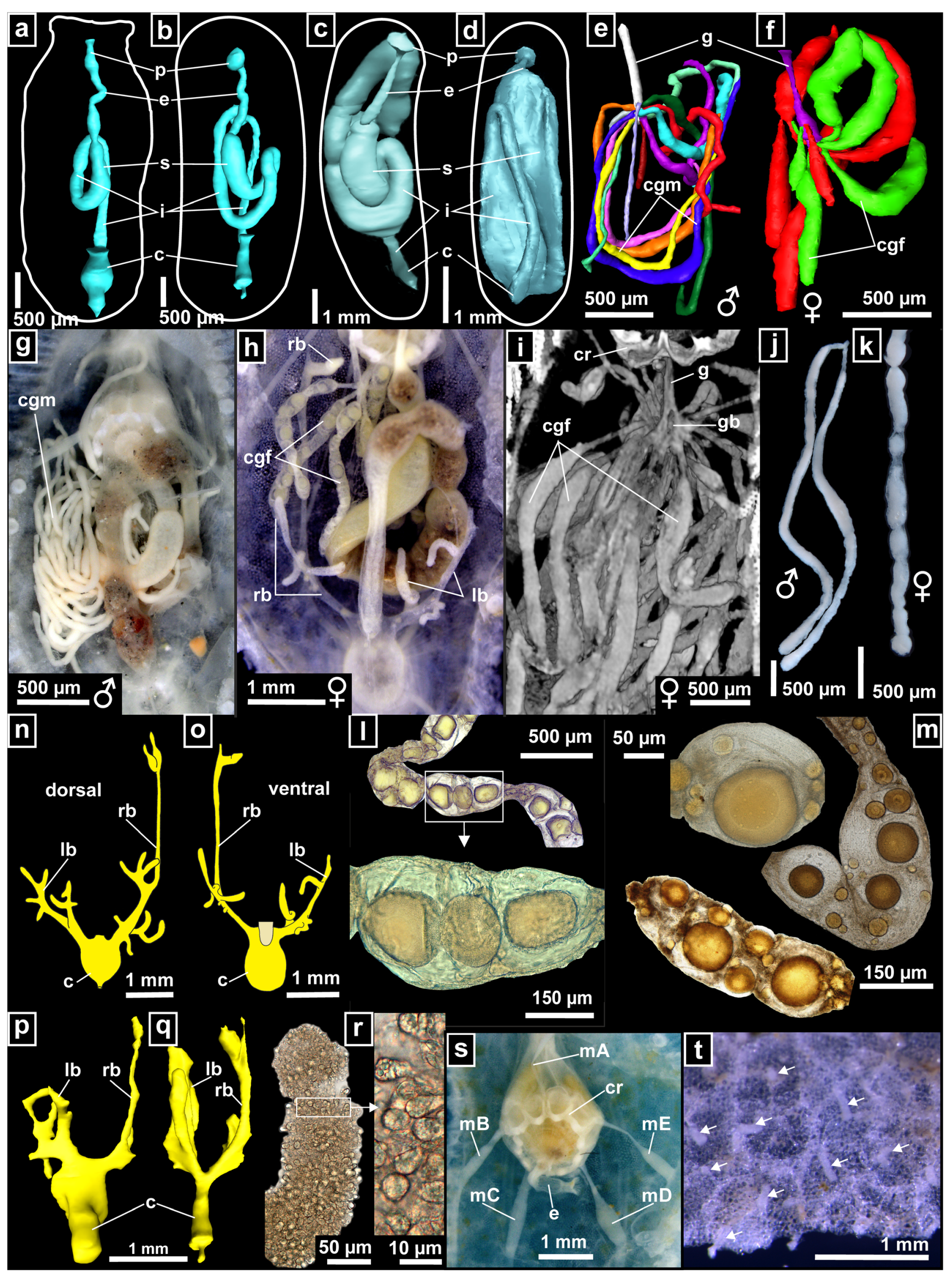

Springer 
Fig. 11 Psolidium bathygalego nom. nov. a-d Different arrangement and repletion of the digestive tract (a-c dorsal, d ventral); e Male gonad; f Female gonad; $\mathbf{g}$ Ventral view of a male specimen; h Ventral view of a female specimen; $\mathbf{i}$ Mature female gonad; $\mathbf{j}$ Two male gonadal tubules; k Poorly developed female gonadal tubule; I Gonadal tubule with developed oocytes; m Different sizes of oocytes; n, o Drawings of respiratory trees in dorsal and ventral view; $\mathbf{p}, \mathbf{q}$ Reconstruction of respiratory trees; $\mathbf{r}$ End of a branch of the respiratory tree and detail of the small rounded vesicles; $\mathbf{s}$ Contracted retractor muscles; $\mathbf{t}$ Irregular reticulation of the possible canals of the dorsal podia (arrows). (a-f, p, q 3 D reconstruction with AVIZO 6.4; i micro-CT)

of lengths between 16.2 and $120.6 \mu \mathrm{m}$ and widths between 15.3 and $105.5 \mu \mathrm{m}$, mostly with a clear spherical configuration (Fig. $11 \mathrm{~m}$ ). In the specimens collected in July (oceanographic campaign A-Selva-2008), most of the oocytes of the gonadal tubules of the females were underdeveloped (Fig. 11k), while in the specimens collected in September (oceanographic campaigns DIVA-Artabria-I-2002, DIVAArtabria-I-2003, DIVA-Artabria-II-2008) the oocytes were more developed and in each gonadal tubule there were oocytes of various sizes (Fig. 111, m). In the numerous specimens studied here, no developing eggs or juveniles were found in the ventral sole, so it can be deduced that Psolidium bathygalego nom. nov. is not an incubator species.

\section{Habitat and feeding}

All Psolidium bathygalego nom. nov. specimens were collected on hard substrata, mostly on phosphorites and carbonate crusts and to a lesser extent on dead coral fragments. Some specimens were also found on gravel of bivalves, fragments of shells, calcareous plates, and small stones (Fig. 2a, b, d).

The specimens live attached to hard surfaces, adapting very well to the substratum, to which they are firmly attached with the perimeter podia of the sole margin. The podia of the internal perimeter row of greater diameter, arranged vertically, anchor the animal to the substratum, while the podia of the external perimeter row of lesser diameter are arranged radially, holding the body margin firmly to the substratum. The gripping by both podia and the articulated disposition of the body plates gives the animal an extraordinary capacity to adapt to the substratum, both on flat surfaces and in hollows or anfractuosities (Fig. 2a, b, d). This capacity to adapt to the irregularities of the substratum determines that they may show either their regularly oblong and convex appearance or an irregular contour and very reduced thickness. They achieve this flattening by tightening the external perimeter podia that pull the margin of the sole, which depresses the back thanks to the flexibility that the overlapping of the dorsal ossicles allows. (Fig. 2a, b, d). When in vivo they are detached from the substratum, they adopt a semi-cylindrical shape, as the lateral margins fold towards the middle of the sole (Fig. 2c).

From the analysis of the digestive contents of several specimens, it can be deduced that Psolidium bathygalego nom. nov. is a suspension-feeder. Most of the specimens examined had a high degree of digestive repletion, in some cases extraordinary, occupying the entire visceral cavity (Fig. 11d). The study of the digestive contents revealed the presence of numerous specimens of different species of Foraminifera, mostly Globigerina, and a few Radiozoa. Abundant organic accumulations with a portion of very fine sediment were also observed, in which diatoms, spicules of Porifera, remains of thecosome Gastropoda, and small fecal balls were also present. The food particles are captured by the oral tentacles, adhering to their mucus-impregnated surface. Each tentacle is possibly introduced individually into the mouth, wiping the podia away with the bifid tentacles, in a similar way as Aslia lefevrei (Barrois, 1882) does it with its branched tentacular podia (Costelloe and Keegan 1984; personal observations). Thus, with the end of the three bifid tentacles, they would surround the whole tentacle, performing an effective food withdrawal. In a preserved specimen, numerous spicules of Porifera, grains of very fine sediment, very small organic particles, and diatoms that still remained attached to the mucus were observed on the entire surface of a completely extended oral tentacle. In general, those specimens that have a normal degree of repletion that does not deform the digestive tract contain very fine sediment, while in specimens with a large or extraordinary repletion, the digestive content is mainly composed of Foraminifera, some of extraordinary size, such as the specimen of Sphaerogypsina globulus (Reuss, 1848) of $330 \mu \mathrm{m}$ in diameter (Fig. 9n, o).

In the photographs in vivo of several specimens taken on board during the campaigns, it can be observed how the dorsal podia of the bivium had Foraminifera and various organic particles attached to their ends (Fig. 2a, d), which allows us to deduce that the dorsal podia are actively involved in the capture of food. It is possible that they transfer food particles from one podium to another in the direction of the oral cone, with oscillatory movements as do the zooids of certain species of Bryozoa. They could be picked up from around the mouth by the tentacles by flexing the introvert which protrudes widely (Fig. 2a).

\section{Geographical distribution}

To date, 959 specimens of Psolidium bathygalego nom. nov. were collected from the bathyal bottoms of Galicia, Asturias, Brittany, the Sicilian Channel and Mauritania, between 274 and $1200 \mathrm{~m}$ deep (Fig. 1). Of these, 939 specimens $(97.9 \%)$ were collected in Galicia (Fig. 1b), 96 by Cherbonnier (1969, 
1970) and 843 in our expeditions (Miguez and Urgorri 1999; Miguez 2009; own data). Of the remaining 20 specimens (2.1\%), 3 were collected in Asturias (Fig. 1b) by FernándezRodríguez et al. (2019), 6 in Brittany (Fig. 1c) by Cherbonnier (1970), 4 in the Sicilian Channel (Italy) (Fig. 1d) by Zibrowius and Taviani (2005), and 7 in Mauritania (Fig. 1e) by Calero (2017). It should be emphasized that of the 939 specimens collected in Galicia, 731 specimens (707 collected in our expeditions and 24 by Cherbonnier $(1969,1970))$ were collected in Ferrol Canyon and Coruña Valley, where phosphorites and carbonate crusts are very abundant. Consequently, Psolidium bathygalego nom. nov. has a North Atlantic-Mediterranean distribution, being especially abundant on the bathyal bottoms of Galicia (NW Iberian Peninsula).

\section{Discussion}

At present, 57 species are recognized within the genus Psolidium (WoRMS 2019; Ong et al. 2019; Martins and Tavares 2020), of which almost all (93\%) have an IndoPacific and Antarctic distribution, with 50\% living on the littoral seabeds and the same number of species $(50 \%)$ on the deep seabeds. $30 \%$ of the species of the genus Psolidium are described from Australian and New Zealand waters, and $16 \%$ are from Antarctic and sub-Antarctic waters. $24 \%$ of the species are known from different locations in the West Asian Pacific. $13 \%$ are distributed in various locations of the American Pacific coast, from Alaska to Chile and Argentina, $10 \%$ were described from South African bottoms and islands of the West African Indian Ocean, and 7\% were described from the Atlantic Ocean (Table 2). In the North Atlantic Ocean only two species of the genus Psolidium are known, one in the Northwest Atlantic Ocean, Psolidium prostratum Pawson \& Valentine, 1981, from the east coast of the USA (North Carolina and South Carolina) between 383 and $450 \mathrm{~m}$ on hard substratum (Pawson and Valentine 1981; Pawson et al. 2009) and the other in the Northeast Atlantic Ocean, Psolidium bathygalego nom. nov. from the bathyal bottoms of SW Europe and W Africa (Galicia, Asturias, Brittany, Sicily Channel and Mauritania) between 274 and $1200 \mathrm{~m}$ on hard substratum (Cherbonnier 1969, 1970; Massin 1997; Calero 2017; Fernández-Rodríguez et al. 2019; Hansson 2001; present data). The two species, although with some external similarity, are clearly distinguishable. Psolidium prostratum Pawson \& Valentine, 1981, has the 10 tentacles dendritic, with two smaller ones; it shows podia on the midventral radius $\mathrm{A}$ and lacks circular plates at the end of the dorsal podía. However, in Psolidium bathygalego nom. nov., the tentacles are not dendritic and three of them are smaller and bifid; there are no podia on the mid-ventral radius $\mathrm{A}$, and the dorsal podia show a circular plate at the end.

In the southwestern Atlantic Ocean, four species were described from coastal and bathyal bottoms: Psolidium dorsipes Ludwig, 1886 and Psolidium disciformis (Théel, 1886) from the Strait of Magellan and Psolidium nanoplax Martins \& Tavares, 2020 and Psolidium lonchostinum Martins \& Tavares, 2020 from Brazil. The presence of tubular podia on the mid-ventral radius A in Psolidium dorsipes Ludwig, 1886 and Psolidium disciformis (Théel 1886), of which Psolidium bathygalego nom. nov. is devoid, clearly differentiates them. Likewise, the ossicles of the ventral sole of $P$. dorsipes, button and cup, and $P$. disciformis, disc-like smooth plates, are very different from those of Psolidium bathygalego nom. nov. (O'Loughlin and Ahearn 2008; Martínez 2014). The small calcareous plates $(150-170 \mu \mathrm{m})$ that cover the dorsal convex surface of Psolidium nanoplax Martins \& Tavares, 2020, are much smaller than those in Psolidium bathygalego nom. nov. $(800-1200 \mu \mathrm{m})$. Furthermore, the presence of knobbed and multiperforated single plates, strongly concave and "cup-like" multiperforated plates, concave, in the sole of Psolidium nanoplax Martins \& Tavares, 2020 differentiates it from Psolidium bathygalego nom. nov. which has flat, smooth, and non-concave sole ossicles and lacks the "cup-like" plates described by Martins and Tavares (2020). Likewise, Psolidium bathygalego nom. nov. differs clearly from Psolidium lonchostinum Martins \& Tavares, 2020, in that the latter shows much shorter calcareous plates of the dorsal convex surface $(100-120 \mu \mathrm{m})$ and branched rods (thorn ossicles) which Psolidium bathygalego nom. nov. lacks. (Martins and Tavares 2020). However, the description of these two species, Psolidium nanoplax Martins \& Tavares, 2020 and Psolidium lonchostinum Martins \& Tavares, 2020, is rather imprecise and brief, since among others, it does not provide any information about the tentacles or their ossicles.

Two other species of the genus Psolidium have their type locality in South Africa, in areas close to the margins of the South Atlantic Ocean, Psolidium pseudopulcherrimum Thandar, 2008 and Psolidium pulcherrimum Thandar, 2008. These two species show inconspicuous dorsal podia and ventral podia in a single row on each side of sole, among other characters that differentiate them from Psolidium bathygalego nom. nov. which has conspicuous dorsal podia and ventral podia in two perimeter rows on the margin of the ventral sole. These characters also differentiate it from another species from the South African Indian coast, Psolidium acorbulum Thandar, 2006 which bears 8 oral tentacles and the sole bordered by a single row of podia laterally (Thandar 2006, 2008).

In the recent diagnoses of the genus Psolidium by O'Loughlin and Maric (2008), O'Loughlin and Ahearn (2008), Davey and Whitfield (2013) and Ong et al. (2019), it 
is established that the species of the genus have ten dendritic tentacles, with two smaller ventral ones, a character that can be verified in the descriptions of many species that inhabit the deep system, Psolidium aequm, $P$. kermadeci, $P$. ramum, $P$. bullatum, $P$. vitreum, $P$. gracile, $P$. panamense, and $P$. prostratum, among others (Davey and Whitfield 2013; Ohshima 1915; Ludwig 1894; Pawson and Valentine 1981) and in other species of the coastal system, Psolidium incubans, $P$. ravum, $P$. berentsae, $P$. hutchingsae, $P$. marshae, $P$. nigrescens, $P$. minutum, $P$. oloughlini, $P$. multipes, among others (Ekman 1925; Hickman 1962; O'Loughlin and Maric 2008; Clark 1938; Mackenzie and Whitfield 2011; Thandar 2006). Some descriptions, however, state that the tentacles of $P$. translucidum were completely retracted and invisible, making it absolutely impossible to count them (Koehler and Vaney 1905); in P. granuliferum and P. spinuliferum, it has not seemed necessary to cut them open to examine the contracted tentacles (Clark 1938); in P. planum the tentacles were not examined (Deichmann 1941).

Furthermore, it should be added that in the descriptions of many of these bathyal and coastal species, the dendritic character of the tentacles is not always specified. It should also be noted that Psolidium acorbulum Thandar, 2006, shows eight finger-shaped tentacles without lateral branches (Thandar 2006) whereas Psolidium bathygalego nom. nov. has ten fingershaped tentacles, without lateral branches and three smaller ones with the end bifid, the pair of radius A and the upper tentacle of radius $\mathrm{C}$. Consequently, the diagnosis of the genus Psolidium as regards the tentacles has been modified: ten dendritic or finger-shaped tentacles, rarely 8 tentacles, the two ventral ones smaller, rarely absent or with the end bifid; sometimes the upper tentacle of radius $\mathrm{C}$ is also small and bifid.

Two descriptions of Psolidium bathygalego nom. nov. are known, the original description by Cherbonnier (1969, as $P$. complanatum) and the description of the first record of a Psolidae in the Mediterranean Sea (Sicilian Channel), by Massin (1997, as P. complanatum). Both descriptions are almost identical to the descriptions in this paper; however, some discrepancies and omissions need to be discussed. Cherbonnier (1969) proves the variability in the number and distribution of the dorsal podia, but states that the sucker of the dorsal podia is not supported by a calcareous disc. However, Massin (1997) does describe the calcareous disc, but as a nodular cup, which does not coincide with what has been observed in our specimens, which lack nodules and have more holes and a larger diameter.

Cherbonnier (1969) describes the existence of ten tentacles, of which eight are large, and two are very small ventromedial tentacles, in the shape of a glove finger totally devoid of lateral branches. Massin (1997), on the other hand, only states that the tentacles are digitiform. Neither of the two authors describes the character of the bifid end of the mid-ventral pair of tentacles, and they did not observe the bifid end of the third upper tentacle of radius $\mathrm{C}$. Regarding the number of external and internal ventral tubular podia, both authors (Cherbonnier 1969; Massin 1997) state that those of the external row are twice as numerous as those of the internal row, although it was found in 92 specimens examined that they are in a proportion from three times (ext./int. $=3$ ) to the same number of podia (ext./int. $=1$ ), although $50 \%$ of the specimens presented a proportion between 1.5 and 2 .

Massin (1997) mentions that between the podia of the internal row and posteriorly along the mid-ventral ambulacrum there are brown spots of pigment whose number and size vary greatly from one specimen to another, a character that is not mentioned by Cherbonnier (1969). In the specimens studied here, the presence of these brown spots has also been detected in many specimens. It has been verified that they are not a surface pigment, but rather that the brown spots are located on the internal surface of the integument of the ventral sole, in the form of oval or shapeless groupings, constituted by small granules (vide supra habitus).

Semi-quantitative chemical analyses under SEM have been performed on the oval clusters between the internal ventral podia (Fig. 3k, m) and on those dispersed on the internal ventral surface of the sole (Fig. 3n), as well as on the small granules agglutinated in shapeless masses (Fig. 3o). A total of 18 samples were analyzed; all were found to have the same elemental composition: $\mathrm{C}, \mathrm{O}, \mathrm{S}, \mathrm{Ca}, \mathrm{Na}, \mathrm{Mg}, \mathrm{Si}, \mathrm{Fe}$, and $\mathrm{K}$, although the concentrations differed, as $\mathrm{C}, \mathrm{O}, \mathrm{S}$, and $\mathrm{Ca}$ were in relatively high concentrations, while $\mathrm{Na}, \mathrm{Mg}, \mathrm{Si}, \mathrm{Fe}$, and $\mathrm{K}$ were in lower concentrations. However, in the small granules agglutinated in shapeless masses (Fig. 3o), the concentration of Fe was as high as those of S and Ca. We do not know the physiological significance of these formations, but they could be brown bodies that have been described from other species of holothuroids and that, according to Jans et al. (1996), are commonly observed in the perivisceral coelom and the watervascular system. They are spherical to ovoid in shape, with a diameter varying from 0.2 to $5 \mathrm{~mm}$.

Neither Cherbonnier (1969) nor Massin (1997) mentions the abundant spiny ossicles found subepithelially in the gonadal tubules of males and females and in the respiratory trees of Psolidium bathygalego nom. nov. However, there are four species of the genus that have ossicles very similar to those of the respiratory trees and the gonadal tubules described here: Psolidium parmatum (Sluiter, 1901), Psolidium nigrescens Clark, 1938, Psolidium ramum Davey \& Whitfield, 2013 and Psolidium lonchostinum Martins \& Tavares, 2020. Clark (1938) calls them triradiate particles in Psolidium nigrescens Clark, 1938, present on the back 


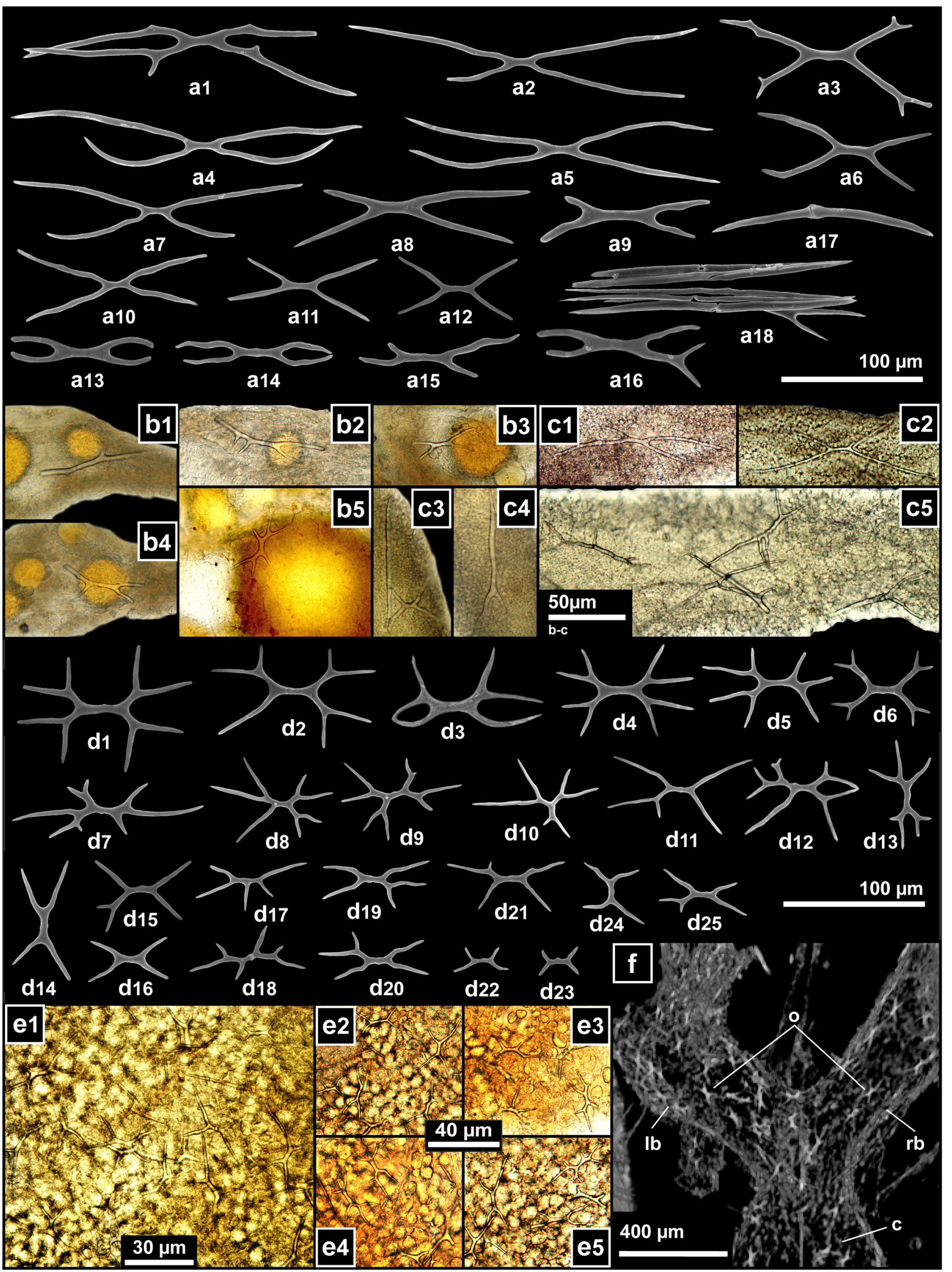

黑 Springer 
Fig. 12 Psolidium bathygalego nom. nov. a SEM images of ossicles of the gonadal tubules of males and females; b, c Ossicles in the gonadal tubules of females (b) and males (c); d SEM images of ossicles of the respiratory trees; e Ossicles in situ in respiratory trees; f Arrangement in situ of the ossicles in the basal branches of the respiratory trees. (a, d SEM; f micro-CT)

and sole; O'Loughlin and Maric (2008) mention them, in the same species, as branched rods with pointed ends ("thorn" ossicles), irregular form, 3-5 arms, flat to 3dimensional, up to $56 \mu \mathrm{m}$ long. Davey and Whitfield (2013) describe them as thorn (branching rod) ossicles, the largest being $135 \mu \mathrm{m}$, in the holotype of Psolidium ramum Davey \& Whitfield, 2013. They state that although the description is based on one specimen, of which the ventral sole was partially destroyed, the distinctive thorn ossicles, while rare, were present in both the dorsal and ventral body wall and have not been reported for any other New Zealand Psolidium species. Martins and Tavares (2020) describe the dorsal presence of branched rods (thorn ossicles) (40-60 $\mu \mathrm{m}$ long) in Psolidium lonchostinum Martins \& Tavares, 2020. Sluiter (1901) did not report their presence in the original description of Psolidium parmatum (Sluiter, 1901), but O'Loughlin and Maric (2008) examined the holotype for their presence. From the study of other specimens, they mention their presence dorsally as irregular branched pointed rod "thorn" ossicles, up to $160 \mu \mathrm{m}$ long and in the sole as "thorn" ossicles up to $96 \mu \mathrm{m}$ long. It should be considered that in all four species the thorn (branching rod) ossicles are rare or not very abundant and from the observation of the figures: Fig. $11 \mathrm{C}$ of P. ramum in Davey and Whitfield (2013); Fig. 2C of P. lonchostinum in Martins and Tavares (2020); Fig. 8c of $P$. parmatus and Fig. $7 f$ of $P$. nigrescens in O'Loughlin and Maric (2008), we can deduce a great similarity with the subepithelial spinous ossicles of the respiratory trees of Psolidium bathygalego nom. nov. (compared respectively with Figs. 12d20, d18, d14, and $\mathrm{d} 23$ of this study) and all of them with a length within a similar range. Consequently, the thorn (branching rod) ossicles are very likely subepithelial spinous ossicles of the respiratory trees, but in these four species, they could have appeared in the preparations of the dorsal or sole ossicles. This is not a trivial statement, as in this study this type of ossicles appeared at the beginning both in preparations of the dorsal ossicles in plate and in those of the ventral sole. Later on, it was found that the epithelium of the respiratory trees of Psolidium bathygalego nom. nov. is intimately attached to the wall of the body by mesenteric connectives, so that in dissection, small portions may remain adhered to the back, mainly of the right branch of the tree (Fig. 11h) or to the sole, especially at the base of the trees (Fig. 9g). However, it is a fact that must be checked on these 4 species (vide supra), but their presence with the dorsal plates does not make much sense as far as their structure is concerned.

Regarding the internal anatomy, Cherbonnier (1969) and Massin (1997) provide very little information, since they describe very briefly the calcareous ring, with a very schematic illustration. Massin (1997) states that the gonad is made of several large white tubes, while Cherbonnier (1969) says that the gonads are composed of a dozen simple tubes containing very large eggs. He also notes the presence of a stone canal, exceptionally two, one of which is very small, a large Polian vesicle and very short retractor muscles, approximately one tenth of the length of the body, attached to wide and flat longitudinal muscles.

Of the internal anatomy of the other species of the genus Psolidium, there are only small descriptions that provide very little information, practically of those characters that can be observed through the ventral sole (Hickman 1962; Thandar 2006, 2008; Lambert 1996; Semper 1867-1868; Sluiter 1901; Augustin 1908). In Psolidium mitsukurii, Augustin (1908) states that the left branch of the respiratory tree is more developed than the right one, contrary to what has been observed in the specimens of Psolidium bathygalego nom. nov. studied here.

In this study, thanks to SEM techniques and above all to computerized microtomography (micro-CT), a very detailed description of the internal anatomy of Psolidium bathygalego nom. nov. is made. This shows that the micro-CT technique is an essential tool in the study of the internal and external anatomy of Echinoderms, obtaining high-quality images, both of the electro-dense structures and of the soft tissues, thanks to the application of staining and dehydration techniques.

In the numerous specimens studied here, no developing eggs or juveniles have been found in the ventral sole, as in P. incubans (Ekman 1925; Hyman 1955); thus, it can be deduced that Psolidium bathygalego nom. nov., is not an incubator species.

Feral and Massin (1982) specify that nothing is known on the role of the cloacal suspensors in the rectum or in the sediment-filled cloaca. However, a large part of the digestive content of Psolidium bathygalego nom. nov. are Foraminifera generally large in size and some with an extraordinary diameter of $330 \mu \mathrm{m}$, such as the specimen of Sphaerogypsina globulus (Reuss, 1848) in Fig. 9n housed under the anal cone. Thus, the animal requires a large cloacal dilation to house and expel these large shells to the outside, and it requires a large 


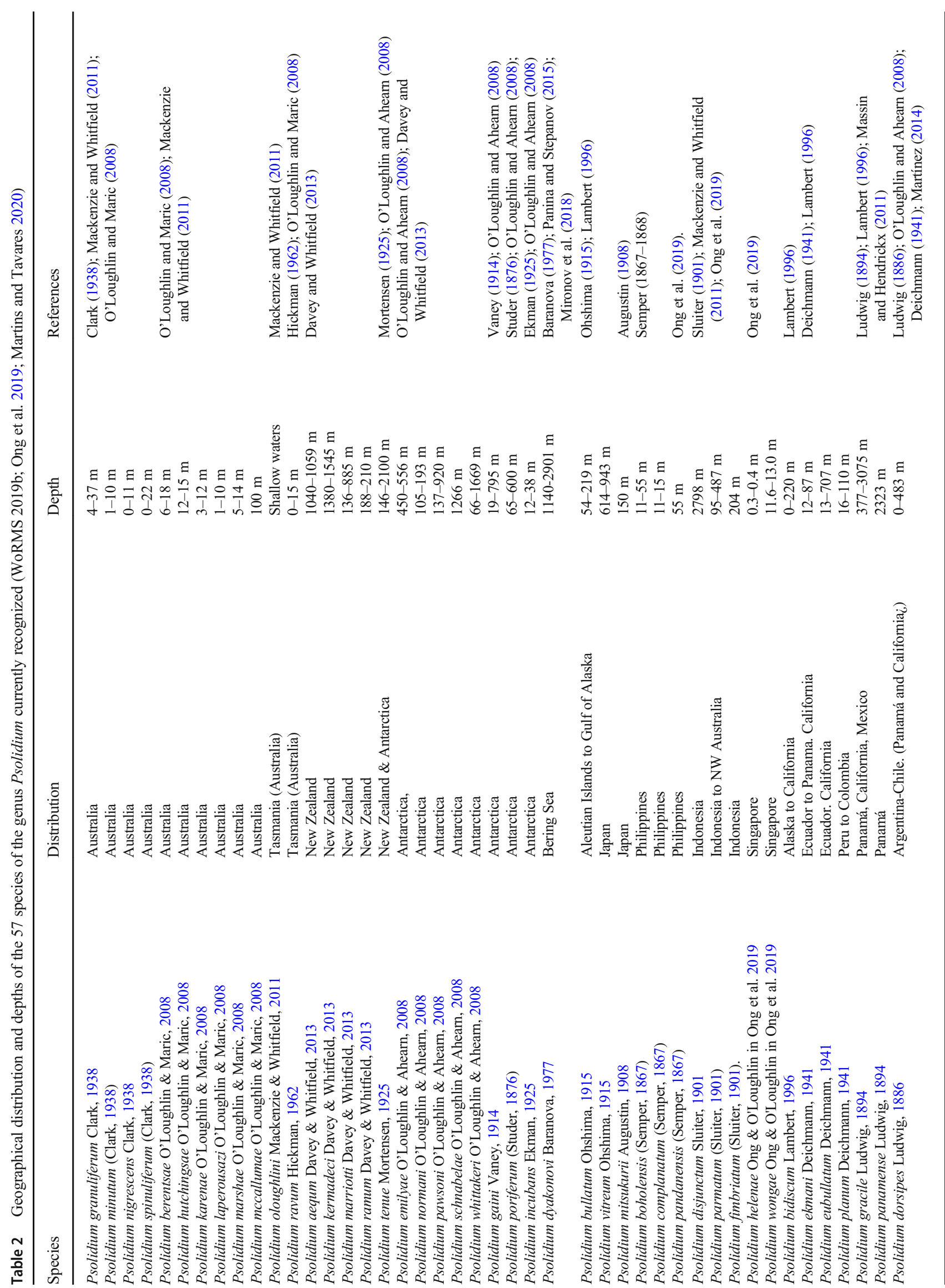




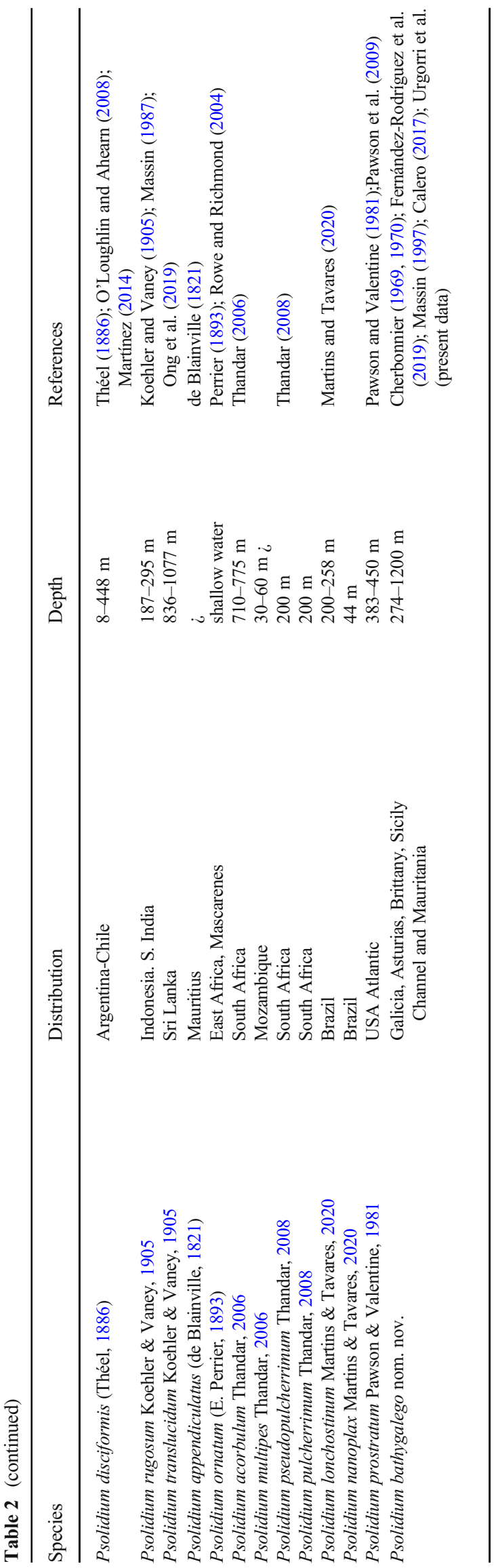

buccopharyngeal dilation for their ingestion in the digestive tract.

On the distribution of Psolidium bathygalego nom. nov. (Fig. 1) Massin (1997) says that there are probably intermediate populations between the NW of the Iberian Peninsula and the Strait of Sicily but that they have yet to be discovered. If we analyze the data from Psolidium bathygalego nom. nov. citations collected outside the NW of the Iberian Peninsula, it turns out that the 7 specimens from Mauritania were collected from cold-water coral reefs and coral fragments, with and without sediment, between 488 and $525 \mathrm{~m}$ depth (Calero 2017; Ramos et al. 2017a, b; Ramil F personal communication); the 4 specimens from Sicilian Channel (Italy) were cited as part of the fauna associated with deep coral and other calcareous substrata, between 274 and $786 \mathrm{~m}$ depth (Massin 1997; Zibrowius and Taviani 2005); the 3 specimens from Avilés Canyon (Asturias) were collected between 790 and $1200 \mathrm{~m}$ depth on rocky and sedimentary substrata of rock and sediments on reef-forming coral bottoms (Fernández-Rodríguez et al. 2019); also, the 6 specimens from Brittany were collected from gravel and coarse sand bottoms at 630-650 m depth (Cherbonnier 1970). Therefore, all these specimens represent only $2.1 \%$ of the specimens collected of Psolidium bathygalego nom. nov. Although they are all from equivalent bathyal depths, they inhabited stony or coral substrata and they clearly represent exiguous populations. However, the specimens collected in Galicia (Cherbonnier 1969, 1970; present data), although also a few specimens inhabited stony or coral bottoms, the most frequent and abundant populations, lived on bottoms of phosphorites and carbonate crusts, being sometimes very abundant with $290,109,68,54$ or 52 specimens in each dredging sample (see Table 1). This shows that these phosphorites bottoms and carbonate crusts (Lamboy and Lucas 1979; González et al. 2016) are the preferred habitat of Psolidium bathygalego nom. nov., bottoms that are strongly influenced by the MOW (Mediterranean Outflow Water). This current flows between 600 and $1500 \mathrm{~m}$. deep, where the fields of phosphorites and carbonate crusts are located. The presence of the MOW is registered through the Atlantic continental slope of the Iberian Peninsula and the Bay of Biscay, and its influence reaches the Norwegian Sea (Somoza et al. 2014). The turbulent mixing between intermediate waters as the warm and saltier MOW with the cold Eastern North Atlantic Central Water subpolar type $\left(\mathrm{ENACW}_{\mathrm{P}}\right)$ provides an ecological niche (Somoza et al. 2014) that is efficiently used by suspension-feeders, epibenthic opportunistic species specialized in capturing food particles from lightly flowing water which causes significantly higher abundances of Foraminifera (Schönfeld 1997) which, as has been proven, are a very important food source in the diet of Psolidium bathygalego nom. nov. The assertion by Massin (1997) of the probable existence of 
intermediate populations is no doubt very plausible, but they should be located on polymetallic nodule bottoms and carbonate crusts, mainly influenced by these high fertilized and remineralizated waters causing high levels of primary production (Bode et al. 2002).

Acknowledgements The authors would like to thank Dr. Marcos P. Señarís, Dr. Ramiro R. Tato, and Dr. Marcos Abad for their collaboration in collecting the samples. We would also like to thank Dr. Fran Ramil and Dr. Belén Calero for the detailed information sent on the samples from Mauritania. We would also like to thank Dr. Luis Somoza for his help in the correct denomination of hard substrata for the sampled bottoms. We would also like to thank Raquel Antón and Ramiro Barreiro from the Electronic Microscopy Service of the USC, for their help in taking the images under SEM. We also want to extend our gratitude to Dr. Celia Besteiro for her help in the identification of the Foraminifera. We would like to thank Dr. Miguel Angel Alonso-Zarazaga, Prof. Serge Gofas and Prof. Kullander for their help in clarifying the ICZN. We thank the editor Sabine Stöhr for her comments which helped to improve the manuscript. We are also very grateful to Julia Garcia who kindly checked the English language. We are grateful to two anonymous reviewers for their comments which have helped to improve this paper.

Funding This publication is a contribution to the projects PGIDT 01 PXI 20008 PR, PGIDIT 05 PXIC20001 PN, PGIDIT07PXB000120PR, and A Selva-08 of the D.X. of I+D+i of the Xunta de Galicia and to VEM2003-20070-C04-04 and CTM2004-00740 of the Ministry of Education and Science, all of them carried out by the Estación de Bioloxía Mariña da Graña of the Universidade de Santiago de Compostela.

\section{Compliance with ethical standards}

Conflict of interest The authors declare that they have no conflict of interest.

Ethical approval All applicable international, national, and/or institutional guidelines for the care and use of animals were followed by the authors.

Sampling and field studies All necessary permits for sampling and observational field studies have been obtained by the authors from the competent authorities.

Data availability Specimens are housed in the collections of the Museo de Historia Natural of the Universidade de Santiago de Compostela (vide post Deposit).

Author contribution All the authors, members of the same research team, have collectively carried out the study presented in this article. All authors read and approved the manuscript.

\section{References}

Alba-Tercedor J, Sánchez-Tocino L (2011) The use of the SkyScan 1172 high-resolution micro-CT to elucidate if the spicules of the sea slugs (Mollusca: Nudibranchia, Opisthobranchia) have a structural or a defensive function. SkyScan Users Meeting 2011:113-121

Augustin E (1908) Über Japanische Seewalzen. Beiträge zur naturgeschichte ostasiens, Abhandlungen der mathematisch- physikalischen Classe, Königlich-Bayerische Akademie der Wissenschaften, Supplement 2(1):1-45, 2pls

Baranova ZI (1977) A new holothurian of the genus Psolidium from the Bering Sea. Issledovaniya Fauny Morei 21(29):109-113

Barrois T (1882) Catalogue des Crustaces podophthalmaires et des Echinodermes recueillis a Concarneau. Lille, p 68

Blainville HMD (1821) Holothuries. Dictionaire des Sciences Naturelles 21:310-319

Blainville HMD (1834) Manuel d'Actinologie ou de Zoophytologie. F.G. Levrault, Paris, Strasbourg. 1-2(i-viii): pp 644

Bode A, Varela M, Casas B, González N (2002) Intrusions of eastern North Atlantic central waters and phytoplankton in the north and northwestern Iberian shelf during spring. J Mar Syst 36:197-218. https://doi.org/10.1016/S0924-7963(02)00187-2

Bruguière JG (1791) Histoire naturelle des vers. Échinodermes. Encyclopédie Méthodique, vol. 1 (= tome sixième: vols. 2,3). 2: pp viii +594

Burmeister H (1837) Handbuch der Naturgeschichte. Zum Gebrauch bei Vorlesungen. Zweite Abtheilung: Zoologie. [book]. xii + pp. 858 [Zoology 369-858] T.C.F. Enslin, Berlin

Calero B (2017) Echinodermata (Ophiuroidea and Holothuroidea) from Northwest Africa. Tesis Doctoral (Ph.D. Thesis). Universidade de Vigo. pp 441

Candás M, Díaz Agras G, Abad M, Barrio L, Cunha-Veira X, Pedrouzo L, Señarís MP, Tato R, García-Álvarez O, Urgorri V (2016) Application of microCT in the study of the anatomy of small marine molluscs. Microsc Anal 23:S8-S11

Candás M, Díaz-Agras G, Urgorri V (2017) First steps in morphological analysis of the of the reproductive system of Doto pinnatifida (Montagu, 1804). Bruker Users Meeting 2017:112-116

Cherbonnier G (1969) Echinodermes recoltes par la "Thalassa" au large des cotes ouest de Bretagne et du golfe de Gascogne. (3-12 aout 1967). Bull Mus Nat Hist Nat, $2^{\mathrm{a}}$ serie, XLI 1:343-361

Cherbonnier G (1970) Echinodermes recoltes par la "Thalassa" au large des cotes d'Espagne et du golfe de Gascogne. (18-25 octobre, 1968). Bull Mus Natn Hist Nat, $2^{\mathrm{a}}$ serie, XLI 5:1266-1277

Clark HL (1938) Echinoderms from Australia, an account of collections made in 1929 and 1932. Memoirs of the Museum of Comparative Zoöology at Harvard College 55:1-597

Costelloe J, Keegan BF (1984) Feeding and related morphological structures in the dendrochirote Aslia lefevrei (Holothuroidea: Echinodermata). Mar Biol 84:135-142. https://doi.org/10.1007/ BF00392998

Davey N, Whitfield E (2013) The Psolidae of New Zealand and some additions to the Macquarie Ridge fauna (Echinodermata: Holothuroidea: Psolidae). Memoirs of Museum Victoria 70:51-67. https://doi.org/10.24199/j.mmv.2013.70.05

Deichmann E (1941) The Holothurioidea collected by the Velero III during the years 1932 to 1938 . Part I, Dendrochirota, Allan Hancock Pacific Exped 8(3):61-195

Ekman S (1925) Holothurien. Further zoological results of the Swedish Antarctic Expedition 1901-1903 1(6):1-194

Faulwetter S, Vasileiadou A, Kouratoras M, Dailianis T, Arvanitidis C (2013) Micro-computed tomography: introducing new dimensions to taxonomy. Zookeys 263:1-45. https://doi.org/10.3897/zookeys. 263.4261

Feral JP, Massin C (1982) Structure and function of the digestive organs: Holothuroidea. In: Lawrence J (ed) Jangoux M. Echinoderm's nutrition. Balkema, Rotterdam, pp 191-212

Fernández-Rodríguez I, Arias A, Anadón N, Acuña JL (2019) Holothurian (Echinodermata) diversity and distribution in the central Cantabrian Sea and the Avilés Canyon System (Bay of Biscay). Zootaxa 4567(2):293325. https://doi.org/10.11646/zootaxa.4567.2.5

Folmer O, Black M, Hoeh W, Lutz R, Vrijenhoek R (1994) DNA primers for amplification of mitochondrial cytochrome $\mathrm{c}$ oxidase subunit I 
from diverse metazoan invertebrates. Mol Mar Biol Biotechnol 3(5): 294-299

Golding RE, Jones AS (2007) Micro-CT as a novel technique for 3D reconstruction of molluscan anatomy. Molluscan Research 27(3): $123-128$

González FJ, Somoza L, Hein JR, Medialdea T, León R, Urgorri V, Reyes J, Martín-Rubí JA (2016) Phosphorites, Co-rich Mn nodules, and $\mathrm{Fe}-\mathrm{Mn}$ crusts from Galicia Bank, NE Atlantic: reflections of Cenozoic tectonics and paleoceanography. Geochem Geophys Geosyst 17(2):346-374. https://doi.org/10.1002/2015GC005861

Grube AE (1840) Actinien, Echinodermen und Würmer des Adriatischen- und Mittelmeers nach eigenen Sammlungen beschrieben. J.H. Bon, Königsberg, p 92

Hansson HG (2001) Echinodermata. In: Costello MJ et al. (Eds.) European register of marine species: a check-list of the marine species in Europe and a bibliography of guides to their identification. Collection Patrimoines Naturels 50:336-351

Haug C, Mayer G, Kutschera V, Waloszek D, Maas A, Haug JT (2011) Imaging and documenting Gammarideans. Int J Zool 2011:1-9. https://doi.org/10.1155/2011/380829

Hickman VV (1962) Tasmanian sea-cucumbers (Holothuroidea). Pap Proc R Soc Tasmania 96:49-72

Hyman LH (1955) The Invertebrates: Echinodermata. In: The coelomate Bilateria, vol IV. McGraw-Hill Book Company, New York, p 763

ICZN - International Commission on Zoological Nomenclature (1999) International Code of Zoological Nomenclature, 4th edn. International Trust for Zoological Nomenclature, London, p 306

Jans D, Dubois P, Jangoux M (1996) Defensive mechanisms of holothuroids (Echinodermata): formation, role, and fate of intracoelomic brown bodies in the sea cucumber Holothuria tubulosa. Cell Tissue Res 283:99-106. https://doi.org/10.1155/ 2011/380829

Koehler R, Vaney C (1905) An account of the deep-sea Holothurioidea collected by the Royal Indian Marine Survey Ship Investigator. [Holothuries recueillies par l'Investigator dans l'Océan Indien. I. Les Holothuries de mer profonde.]. In: Alcock A (ed) Echinoderma of the Indian Museum. Indian Museum, Holothurioidea. Calcutta, pp 1-124

Lambert P (1996) Psolidium bidiscum, a new shallow-water psolid sea cucumber (Echinodermata: Holothuroidea) from the northeastern Pacific, previously misidentified as Psolidium bullatum Ohshima. Can J Zool 74(1):20-31. https://doi.org/10.1139/z96-004

Lamboy M, Lucas J (1979) Les phosphorites de la marge nord de l'Espagne. Etude géologique et pétrographique. Oceanol Acta 2(3): $325-337$

Ludwig H (1886) Die von G. Chierchia auf der Fahrt der Kgl. Ital. Corvette "Vettor Pisani" gesammelten Holothurien. Zoologische Jahrbücher. Zeitschrift für Systematik, Geographie und Biologie der Thiere 2(I):1-36

Ludwig H (1894) The Holothurioidea. In: Reports on an exploration off the west coasts of Mexico, Central and South America, and off the Galapagos Islands, in charge of Alexander Agassiz, by the U. S. Fish Commission Steamer "Albatross," during 1891, Lieut. Commander Z. L. Tanner, U.S.N., commanding. XII. Memoirs of the Museum of Comparative Zoölogy at Harvard College 17(3):1-183

Mackenzie M, Whitfield E (2011) An overview of the Australian psolid sea cucumbers (Echinodermata: Holothuroidea: Psolidae) with the description of 5 new species. Zootaxa 3037:21-36. https://doi.org/ 10.11646/zootaxa.3037.1.2

Martínez MI (2014) Diversidad de Dendrochirotida en el Mar Argentino (Echinodermata: Holothuroidea); aspectos taxonómicos, filogéneticos, ecológicos y biogeográficos. Tesis Doctoral (Ph.D. Thesis), Facultad de Ciencias Exactas y Naturales, Universidad de Buenos Aires. pp 150

Martins L, Tavares M (2020) First record of psolid sea cucumber Psolidium (Holothuroidea: Dendrochirotida: Psolidae) from the
Brazilian coast, with the description of two new species. Zool Stud 59:1-10. https://doi.org/10.6620/ZS.2020.59-02

Massin C (1987) Holothuries nouvelles et peu connues recoltees en Indonesie au cours de la Snellius - 2 expedition. Bulletin de l'Institut Royal des Sciences Naturelles de Belgique, Biologie 57: $97-121$

Massin C (1997) First record of a Psolidae (Holothuroidea, Echinodermata) in the Mediterranean Sea (Sicilian Channel). Bulletin de l'Institut Royal des Sciences Naturelles de Belgique, Biologie 67:101-106

Massin C, Hendrickx ME (2011) Deep-water Holothuroidea (Echinodermata) collected during the TALUD cruises off the Pacific coast of Mexico, with the description of two new species. Revista Mexicana de Biodiversidad 82:413-443. https://doi.org/10. 22201/ib.20078706e.2011.2.476

Miguez L (2009) Equinodermos (Crinoideos, Equinoideos y Holothuroideos), litorales, batiales y abisales de Galicia. Tesis Doctoral (Ph.D. Thesis), Facultade de Bioloxía. Universidade de Santiago de Compostela. pp 846

Miguez L, Urgorri V (1999) Morphology of the calcareous structures of Psolidium complanatum Cherbonnier, 1969 (Echinodermata, Holothuroidea), using a scanning microscope. In: Candia Carnevali MD, Bonasoro F (eds) Echinoderm Research 1998: Proceedings of the Fifth European Conference on Echinoderms, Milan, Italy, 7-12 September 1998. A.A. Balkema, Rotterdam / Brookfield, p 30

Miller AK, Kerr AM, Paulay G, Reich M, Wilson NG, Carvajal JI, Rouse GW (2017) Molecular phylogeny of extant Holothuroidea (Echinodermata). Mol Phylogenet Evol 111:110-131. https://doi. org/10.1016/j.ympev.2017.02.014

Mironov AN, Minin KV, Dilman AB, Smirnov IS (2018) Deep-sea echinoderms of the Sea of Okhotsk. Deep-Sea Res II Top Stud Oceanogr 154:342-357. https://doi.org/10.1016/j.dsr2.2017.10.003

Mortensen T (1925) On a small collection of echinoderms from the Antarctic Sea. Arkiv för Zoologie 17A(31):1-12

O'Loughlin PM, Ahearn C (2008) Antarctic and Sub-Antarctic species of Psolidium Ludwig (Echinodermata: Holothuroidea: Psolidae). Memoirs of Museum Victoria 65:23-42. https://doi.org/10.24199/ j.mmv.2008.65.2

O'Loughlin PM, Maric D (2008) Australian species of Psolidium Ludwig (Echinodermata: Holothuroidea: Psolidae). Memoirs of Museum Victoria 65:1-22. https://doi.org/10.24199/j.mmv.2008.65.1

Ohshima H (1915) Report on the Holothurians collected by the United States Fisheries Steamer "Albatross" in the northwestern Pacific during the summer of 1906. Proceedings of the United States National Museum 48(2073):213-291. https://doi.org/10.5479/si. 00963801.48-2073.213

Okanishi M, Fujita T, Maekawa Y, Sasaki T (2017) Non-destructive morphological observations of the fleshy brittle star, Asteronyx loveni using micro-computed tomography (Echinodermata, Ophiuroidea, Euryalida). Zookeys 663:1-19. https://doi.org/10. 3897/zookeys.663.11413

Ong JY, Wong HPS, O’Loughlin PM (2019) Two new tropical psolid sea cucumbers from the Strait of Johor, Singapore (Echinodermata: Holothuroidea) with a key to Psolidium species from the tropical East Indian-West Pacific region. Raffles Bull Zool 67:206-216. https://doi.org/10.26107/RBZ-2019-0017

Panina EG, Stepanov VG (2015) List of species of the sea cucumbers (Holothuroidea) in the Far-Eastern seas of Russia, VI. Family Psolidae (Echinodermata: Holothuroidea: Dendrochirotida). Bull Kamchatka State Technical Univ 34:88-101. https://doi.org/10. 17217/2079-0333-2015-34-88-101

Parapar J, Moreira J, Helgason GV (2015) First record of genus Orbiniella Day, 1954 (Polychaeta: Orbiniidae) in North Atlantic Ocean with the description of a new species. Zootaxa 4006(2): 330-346. https://doi.org/10.11646/zootaxa.4006.2.5 
Parapar J, Moreira J, O’Reilly M (2016) A new species of Terebellides (Polychaeta: Trichobranchidae) from Scottish waters with an insight into branchial morphology. Mar Biodivers 46(1):211-225. https:// doi.org/10.1007/s12526-015-0353-5

Parapar J, Candás M, Cunha-Veira X, Moreira J (2017) Exploring annelid anatomy using micro-computed tomography: a taxonomic approach. Zool Anz 270:19-42. https://doi.org/10.1016/j.jcz.2017. 09.001

Pawson DL, Valentine JF (1981) Psolidium prostratum, new species, from off the East Coast of the U.S.A. (Echinodermata: Holothuroidea). Proc Biol Soc Wash 94(2):450-545

Pawson DL, Vance DJ, Messing CG, Solis-Marin FA, Mah CL (2009) Echinodermata of the Gulf of Mexico. In: Felder DL, Camp DK (eds) Gulf of Mexico-Origins, Waters, and Biota. Biodiversity. Texas A\&M Press, College S, pp 1177-1204

Perrier JOE (1893) Description d'une espece nouvelle d'Holothurie bilaterale (Georisia ornata E. Perrier). C.R. Ac Sci 116:557-560

Ramos A, Sanz JL, Ramil F, Agudo LM, Presas-Navarro C (2017a) The giant cold-water coral mounds barrier off Mauritania. In: Ramos A, Ramil F, Sanz J (eds) Deep-Sea Ecosystems Off Mauritania. Springer, Dordrecht, pp 481-525. https://doi.org/10.1007/978-94024-1023-5 13

Ramos A, Ramil $\bar{F}$, Sanz JL, Presas Navarro C (2017b) A first insight into the megabenthos of Mauritanian canyons. In: Ramos A, Ramil F, Sanz J (eds) Deep-Sea Ecosystems Off Mauritania. Springer, Dordrecht. pp. 527-559. https://doi.org/10.1007/978-94-024-10235_14

Reuss AE (1848) Die Fossilen Polyparien des Wiener Tertiärbeckens. Naturw Abh 2(1):1-109

Rowe FWE, Richmond MD (2004) A preliminary account of the shallow-water echinoderms of Rodrigues, Mauritius, western Indian Ocean. J Nat Hist 38:3273-3314. https://doi.org/10.1080/ 002229301695105

Schönfeld J (1997) The impact of the Mediterranean Outflow Water (MOW) on benthic foraminiferal assemblages and surface sediments at the southern Portuguese continental margin. Mar Micropaleontol 29(3-4):211-236. https://doi.org/10.1016/S03778398(96)00050-3

Semper C (1867-1868) Holothurien. In: Semper C (ed.). Reisen im Archipel der Philippinen. Zweiter Theil. Wissenschaftliche Resultate. Erster Band. Leipzig: W. Engelmann. iv + 288 pp. $[1867=$ pp. $1-70$, pls. $1-15 ; 1867 /(1868)=$ pp. $71-100$, pls. $16-$ $25 ; 1868=$ pp. $101-288$, pls. 26-40]

Sluiter CP (1901) Die Holothurien der Siboga-Expedition. In: Weber M (ed.): Siboga Expeditie (Uitkomsten op zoologisch, botanisch, oceanograpisch en geologisch gebied verzameld in Nederlandsch Oost-Indië 1899-1900 aan boord H. M. Siboga onder commando van Luitenant ter zee $1^{\mathrm{e}} \mathrm{kl}$. G. F. Tydeman), Monograph XLIV: 142 pp
Somoza L, Ercilla G, Urgorri V, León R, Medialdea T, Paredes M, González FJ, Nombela MA (2014) Detection and mapping of cold-water coral mounds and living Lophelia reefs in the Galicia Bank, Atlantic NW Iberia margin. Mar Geol 349:73-90. https:// doi.org/10.1016/j.margeo.2013.12.017

Stöhr S, Clark EG, Thuy B, Darroch SAF (2019) Comparison of 2D SEM imaging with 3D micro-tomographic imaging for phylogenetic inference in brittle stars (Echinodermata: Ophiuroidea). Zoosymposia 15:146-158. https://doi.org/10.11646/zoosymposia.15.1.17

Studer T (1876) Echinodermen aus dem antarktischen Meere und zwei neue Seeigel von den Papua-Inseln, gesammelt auf der Reise S.M.S. Gazelle um die Erde. Monatsbericht der königlich preussischen Akademie der Wissenschaften zu Berlin. pp 452-465

Thandar AS (2006) New species and new records of dendrochirotid and dactylochirotid holothuroids (Echinodermata: Holothuroidea) from off the east coast of South Africa. Zootaxa 1245:1-51. https://doi. org/10.11646/zootaxa.1245.1.1

Thandar AS (2008) Additions to the holothuroid fauna of the southern African temperate faunistic provinces, with descriptions of new species. Zootaxa 1697:1-57. https://doi.org/10.11646/zootaxa.1697.1.1

Théel H (1886) Report on the Holothurioidea collected by H.M.S. challenger during the years 1873-76. Part II. Report on the scientific results of the voyage of H.M.S. challenger during the years 187376. Zoology 14(part 39):1-290

Vaney MC (1914) Holothuries. In: Deuxième Expédition Antarctique Française (1908-1910) commandée par le Dr Jean Charcot. Sciences Naturelles: Documents Scientifiques. Masson et Cie, Paris, pp 1-54

WoRMS (2019). Psolidium Ludwig, 1886. Accessed at: http://www. marinespecies.org/aphia.php? $\mathrm{p}=$ taxdetails $\& \mathrm{id}=123505$. on 2019$11-16$

Zibrowius H, Taviani M (2005) Remarkable sessile fauna associated with deep coral and other calcareous substrates in the strait of Sicily, Mediterranean Sea. In: Freiwald A, Roberts JM (eds) Cold-water corals and ecosystems. Springer-Verlag, Berlin Heidelberg, pp $807-$ 819. https://doi.org/10.1007/3-540-27673-4_42

Ziegler A (2012) Broad application of non-invasive imaging techniques to echinoids and other echinoderm taxa. Zoosymposia 7:53-70. https://doi.org/10.11646/zoosymposia.7.1.6

Ziegler A, Faber C, Mueller S, Bartolomaeus T (2008) Systematic comparison and reconstruction of sea urchin (Echinoidea) internal anatomy: a novel approach using magnetic resonance imaging. BMC Biol 6:33. https://doi.org/10.1186/1741-7007-6-33

Publisher's note Springer Nature remains neutral with regard to jurisdictional claims in published maps and institutional affiliations. 